\section{Evolución del color en el alero de la fachada del rey D. Pedro I, Real Alcázar de Sevilla. Aportaciones del estudio de materiales a la identificación de las intervenciones de restauración a lo largo de su historia}

\section{The evolution of the colour in the eaves of the façade of the palace of the king Pedro I, Royal Palace of Seville. Contribution of the study of materials to the identification of the conservation works undertaken throughout its history}

\author{
Olimpia López Cruz \\ Ana García Bueno \\ Víctor J. Medina Flórez* \\ Universidad de Granada'
}

verde de As y Cu, amarillo de plomo y estaño, amarillo de cromo, litargirio y negro orgánico. El estudio textural detallado y la precisa caracterización de los pigmentos ha permitido la datación y la correlación espacial de las sucesivas intervenciones sobre la policromía de la fachada.

Con respecto a los pigmentos originales, se han hallado restos de rojo de plomo y cinabrio seguidos por capas de cinabrio/ bermellón, azurita y malaquita de origen natural. En policromías de etapas intermedias, situadas entre los siglos XVI y XVIII, se ha detectado que el cinabrio es sustituido por bermellón y la azurita natural por sintética. En intervenciones más recientes el pigmento más utilizado es el verde esmeralda (sintetizado en 1814) que constituye un nivel de referencia. A partir de finales del siglo XIX, algunos verdes esmeraldas y azules de azurita sintética son sustituidos por azul ultramar sintético.

Palabras clave: arte mudéjar, policromía, pigmentos, aglutinantes, corla, oro, preparaciones, soporte madera, alero.

\section{Abstract}

Results from the research carried out on the polychrome decoration of the façade of the King Pedro I Palace, which was built as part of the Alcázar of Seville between 1356 and 1366, are here explained. This building is regarded as one of the most important examples of architecture from al-Andalus in the Iberian Peninsula. The polychromy of its façade has been subject to numerous interventions throughout its history, but its general appearance remains largely unchanged, variations can be observed in details though. The predominant finishing has always been golden, on a background of reds, blues and greens. After an accuracy painstaking and sampling fieldwork, various laboratory techniques were brought together to identify and study the inorganic and organic phases that comprise the pictorial layers. Such techniques include optical microscopy with reflected and transmitted light, $\mathrm{X}$-rays powder diffraction, scanning electron microscopy with EDX microanalysis, gas chromatography and high pressure liquid chromatography.

At least eight polychrome decorations have been identified, corresponding to different levels carried out in different epochs. Each decoration has usually several layers: preparatory, base, and pictorial or golden foil layer, being the latter the most commonly used as finishing layer.

The decorations use a wide variety of pigments: red lead, cinnabar/vermilion, lead white, natural and synthetic azurite, synthetic ultramarine, malachite, emerald green, As-Cu green, lead-tin yellow, chrome yellow, yellow litharge, and organic black. Detailed study of the textures and the precise characterization of the pigments used on the façade have enabled the successive interventions to be dated and their spatial correlation to be identified.

Regarding the original pigments, remains of lead red and cinnabar were found, followed by layers of cinnabar/vermilion, azurite and malachite, these of natural origin. It was identified that in those decorations dated between the 16th and 18th century cinnabar is replaced by vermilion, and natural azurite is replaced by its synthetic equivalent. More recent interventions reveal that the most widely-used pigment is emerald green (synthesised from 1814 onwards), this constituting a reference level. From the late 19th century onwards, some emerald greens and synthetic azurite blues are replaced by synthetic ultramarine.

Key words: Mudejar art, polychromy, pigments, binding media, coloured varnish, gold, preparatory layer, wood support, eave.

\footnotetext{
* olimpia@ugr.es, anagar@ugr.es, vmedina@ugr.es

${ }^{1}$ Queremos expresar nuestro agradecimiento al Patronato de los Reales Alcázares de Sevilla y a su director D. Antonio Balón Alcalá por haber permitido el estudio de los paramentos de la fachada principal del Palacio de Don Pedro I. Al Dr. Mineralogía y Petrología de la Universidad de Granada y a su director, Dr. Miguel Ortega Huertas por habernos facilitado la utilización de diverso instru-

mental científico. Al Dr. Nicolás Velilla Sánchez por su asesoramiento y apoyo.
} Antonio Almagro Gorbea por su revisión crítica del texto. Al Departamento de Las policromías incluyen una amplia variedad de pigmentos: rojo sintética, azul ultramar sintético, malaquita, verde esmeralda,
\end{abstract}




\section{INTRODUCCIÓN}

El estudio previo a la restauración de una obra artística no solo proporciona información sobre aspectos relacionados con la conservación de los materiales o su estado de deterioro, sino que también se ofrece, en sí mismo, como un método de reconocimiento de la propia obra.

La aplicación de un método estratigráfico al estudio de la decoración arquitectónica permite identificar las sucesivas etapas constructivas de la obra y la evolución que ésta ha sufrido a lo largo del tiempo. El método pone en relación su parte visible con la estructura interna de los revestimientos policromos, lo cual implica el estudio de las modificaciones que se producen, no sólo por las alteraciones debidas a los agentes de deterioro sino también por las intervenciones de restauración o mantenimiento que normalmente se hayan realizado o por los cambios en los gustos estéticos. En ocasiones, estas intervenciones suelen producir cambios tanto en el aspecto como en la estructura de la obra a estudiar y forzosamente han de ser tenidas en cuenta. Por ello, hoy en día, se considera fundamental complementarla con estudios técnicos que permitan conocer la naturaleza de los materiales y su secuencia estratigráfica.

Algunos autores (Brogiolo, 1995, pp. 31-35) defienden que la arqueología estratigráfica no es suficiente para entender esta compleja información ya que, si bien identifica las sucesivas etapas constructivas del objeto estudiado, por sí misma no es capaz de interpretar su resultado si no se complementa con el análisis histórico.

Un caso muy significativo de este tipo de situación lo tenemos en el Real Alcázar de Sevilla, concretamente en la fachada del Palacio de Pedro I, en cuyos estudios, previos a las diferentes fases de restauración, hemos tenido ocasión de participar².

El uso y titularidad del monumento han influido en la calidad de las intervenciones de mantenimiento que trataron de recuperar su aspecto inicial ante el deterioro sufrido. Todas ellas fueron especialmente cuidadas, tanto en su origen como en las sucesivas actuaciones que se sucedieron a lo largo del tiempo. La ubicación de algunos de sus elementos plantea una cierta dificultad en su accesibilidad, lo que ha motivado que las distintas intervenciones, ya sean integrales o parciales, estuviesen localizadas en el tiempo y correspondiendo a fechas concretas.

\footnotetext{
2 Este artículo es una parte del estudio completo de la fachada que se está realizando. Dicho estudio se ha llevado a cabo antes y durante la intervención de restauración, iniciada en 2006 y finalizada en 2010. Actualmente nuestro equipo continúa procesando y estudiando la ingente información obtenida a lo largo de este tiempo (véase Almagro et. al., 2009, 2010, 2011).
}

La interpretación de toda esta información, requiere de un estudio complejo y de la puesta apunto de una metodología apropiada. El estudio que presentamos trata de establecer relaciones entre los datos obtenidos a partir del estudio científico de los materiales, los conocimientos técnicos sobre la práctica artística y restauradora, y los datos históricos que nos ofrece la documentación historiográfica; para así, conjuntamente, obtener una visión de la evolución cromática que se da en el alero del Palacio de Pedro I, de los Reales Alcázares de Sevilla, a través de su historia.

\section{REFERENCIA HISTÓRICA Y OBJETIVOS}

El palacio del rey D. Pedro se edificó, entre los años 1356 y 1366. Su fachada principal que se construyó como un elemento de representación, consta de tres cuerpos. El central de mayor altura, objeto de este trabajo ${ }^{3}$, constituye en si mismo un autentico manifiesto de la arquitectura mudéjar que recuerda a antiguos esquemas musulmanes $\mathrm{y}$, posiblemente, a los modelos bizantinos de las fachadas de palacios que eran concebidas como "puerta de la justicia» (Lleo Cañal, 2002, p. 23) (Fig. 1).

El elemento más representativo de esta portada es el alero, realizado en madera tallada cuyas dimensiones son muestra de la relevancia que presenta en el conjunto: 2,50 $\mathrm{m}$. de vuelo, 10,50 m de largo y $3 \mathrm{~m}$ de altura frontal. Está constituido por canecillos que quedan delimitados por dos grandes ménsulas que sostienen el tejaroz y se apoyan en dos pilastras de ladrillo sostenidas por dos columnas de mármol blanco con capiteles almohades que enmarcan la portada. El arrocabe que decora el fondo del muro bajo el alero arranca de delgadas columnitas que apoyan una cenefa con una frase en árabe "La felicidad cumplida» (Gestoso, 1899 pp. 34-35). La zona superior se divide en tres bandas, separadas por tocaduras. Las inferiores son planas y contienen una decoración epigráfica con escudos de León, de Castilla y de la Banda. La intermedia presenta decoración alternante de arcos simples y dobles que están decorados con hojas de palma. La tercera está formada por un friso de mocárabes dorados con dibujos de policromías alternantes en azules y rojas que terminan con los modelos heráldicos ya mencionados y sobre los que se apoya una tabica de la que emergen los canecillos del alero.

\footnotetext{
${ }^{3}$ El estudio de la policromía de este alero es el objetivo fundamental del presente trabajo. Los cuerpos laterales también cuentan con aleros, aunque de menor envergadura, que igualmente están siendo estudiados por nuestro equipo dentro del Proyecto de Investigación «Estudio y conservación de la decoración arquitectónica de tradición islámica» (HUM-02829), cuya financiación ha permitido la realización de este trabajo.
} 
Fig. 1. Fachada del Palacio del rey Pedro I en el Real Alcázar de Sevilla

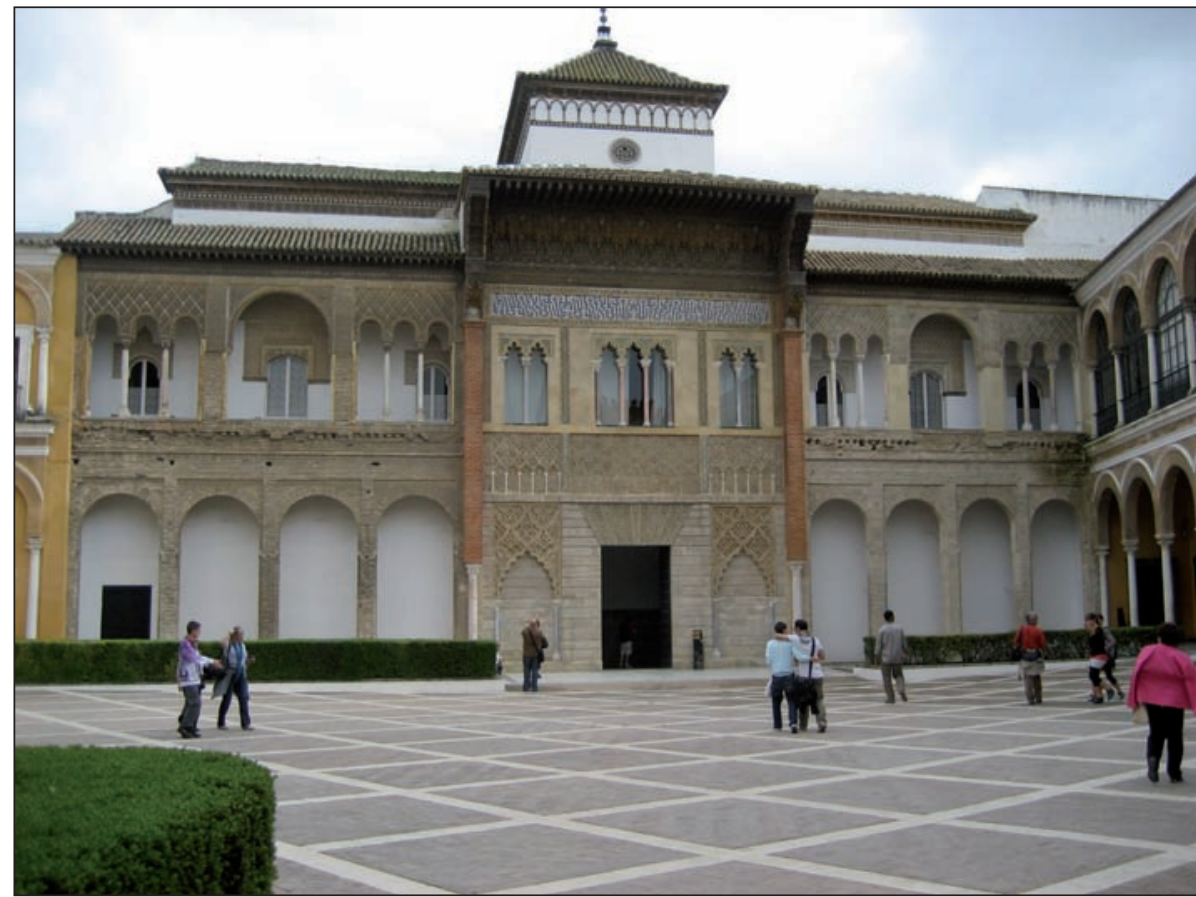

Gran parte de las constantes remodelaciones y rehabilitaciones que ha tenido todo el Alcázar a lo largo de su historia, referenciadas históricamente, son muestra de la constante preocupación por el estado de conservación del monumento y se producen como consecuencia de ser el palacio en uso más antiguo de la monarquía española. Esta circunstancia es la que ha propiciado que el Real Alcázar sea un monumento vivo conservado a través del tiempo, pero también que los acabados originales se encuentren, en muchos casos, ocultos tras un considerable número de remodelaciones. Las intervenciones se acentúan, sobre todo, en el caso de las policromías. Se tiene constancia de diversos repolicromados en la fachada, tanto en yeserías como en maderas que están perfectamente identificados y datados

La ya aludida constancia documental de numerosas intervenciones realizadas sobre esta fachada y la constatación, desde los primeros momentos del estudio material, de la existencia de numerosas capas de repolicromado, así como de la evidencia de que se producían modificaciones del color en las distintas superposiciones, llevaron al equipo a plantearse profundizar en el estudio de la evolución cromática de este imponente alero (Fig. 2).

Los objetivos que se han planteado en el presente trabajo han sido:

- Identificar los estratos de policromía aplicados en las diferentes intervenciones llevadas a cabo a lo largo de la historia.
- Establecer, en la medida de lo posible, una correlación estratigráfica entre las muestras estudiadas, para poder identificar y diferenciar los re-policromados aplicados.

- Comprobar, hasta donde haya información, cómo ha evolucionado el color en el alero a lo largo de su historia.

\section{METODOLOGÍA}

Para poder hacer un estudio sobre la evolución cromática del alero resultaba fundamental establecer una correlación estratigráfica entre las muestras, ya que el hecho de no presentar el mismo número de estratos, en principio, hacía muy difícil realizar comparaciones relativas y establecer conclusiones. En este sentido, hubo que poner a punto una metodología específica, dado el elevado, número de estratos y policromías existentes.

En algunos de estos casos, la superposición se debía a distintas intervenciones, como ejemplo podemos citar el estudio de la policromía de las yeserías del oratorio de la Madraza de Yusuf I de Granada (1349), si bien, en esta ocasión, a pesar de haber sido repolicromadas, solo presentaban dos estratos, el original y el de la restauración. Igualmente ocurría en el Cuarto Real de Santo Domingo de Granada (qubba nazari de la primera mitad del siglo XIV) en el que la policromía original se encontraba oculta por varias capas de enjalbegado blanco que separaban claramente los pigmentos originales de las in- 


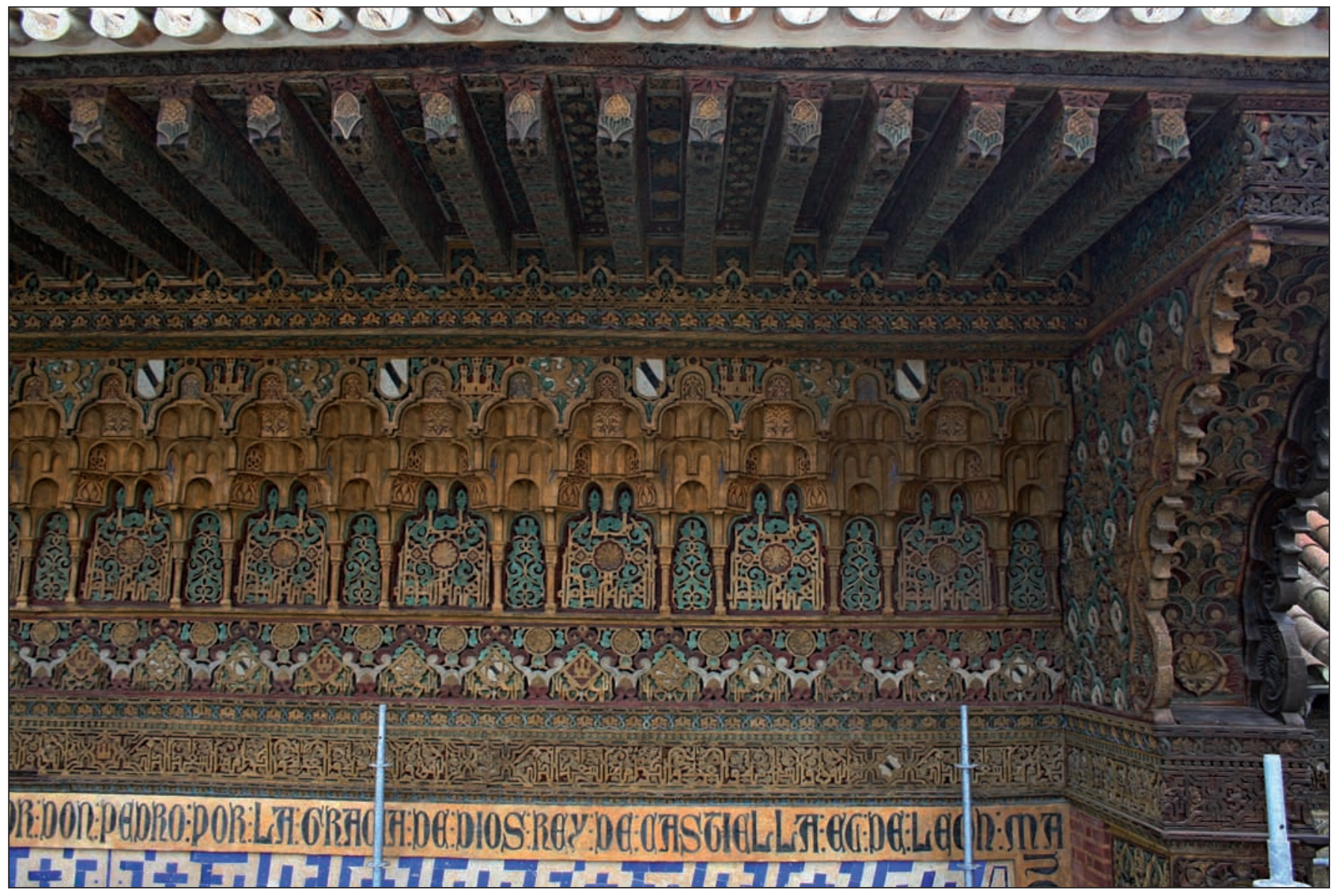

Fig. 2. Estado actual del alero de la fachada del Palacio de Pedro I tras la restauración del año 2008

tervenciones posteriores. Así podríamos citar numerosos ejemplos.

En otros casos, las diferentes capas de color superpuestas se corresponden a una misma policromía, como consecuencia de aplicar, sobre una base o fondo, tanto la capa pictórica principal como los detalles, de otro color. Este es

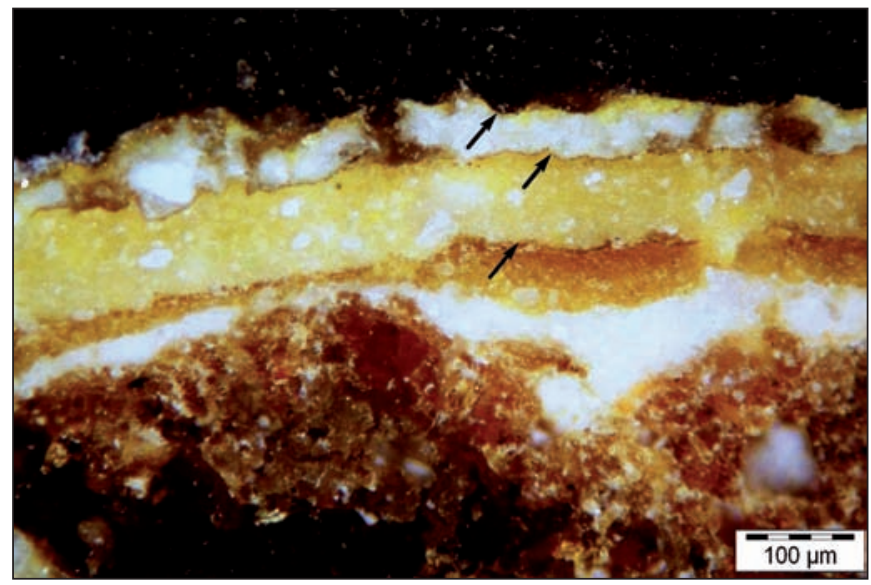

Fig. 3. Imagen de varias capas de oro de distintas policromías con sus respectivas capas preparatorias el caso, por ejemplo, de las pinturas murales de Qusayr 'Amra (Jordania), en las que se identificaron tres estratos de color en el manto del Califa que no son consecuencia de una restauración, sino del proceso de ejecución de la pintura ${ }^{4}$.

En el caso del alero, se daban ambas circunstancias. Así, la constatación de diferentes estratos dorados superpuestos, resultaban indicativos de la existencia de policromías diferentes.

El examen comparativo detallado de toda la información obtenida a partir del estudio de la secuencia estratigráfica, de los resultados del estudio de materiales y de la

${ }^{4}$ El tono general del manto era rojo. Para ello se aplicó una primera capa de rojo de plomo (pigmento más económico) y sobre ella una fina capa de cinabrio (de mayor coste y de color rojo muy intenso); de este modo se conseguía un color muy intenso con menor coste. A continuación se aplicó en los bordes del manto una franja de color azul y sobre ella un perlado de color rojo. Si se observa una estratigrafía de este tipo se podría pensar que algunos de estos estratos son consecuencia de la aplicación de repintes, aunque conociendo la obra en profundidad la interpretación es clara: los estratos no corresponden a una intervención de restauración si no a la pintura original (Informe inédito realizado por los autores, para la restauración de las pinturas murales de Qusayr 'Amra, Jordania, llevado a cabo durante los meses de octubre y noviembre de 1996). 


\section{Alcázar Sevilla Fachada principal Alero M12 (Sofitos)}
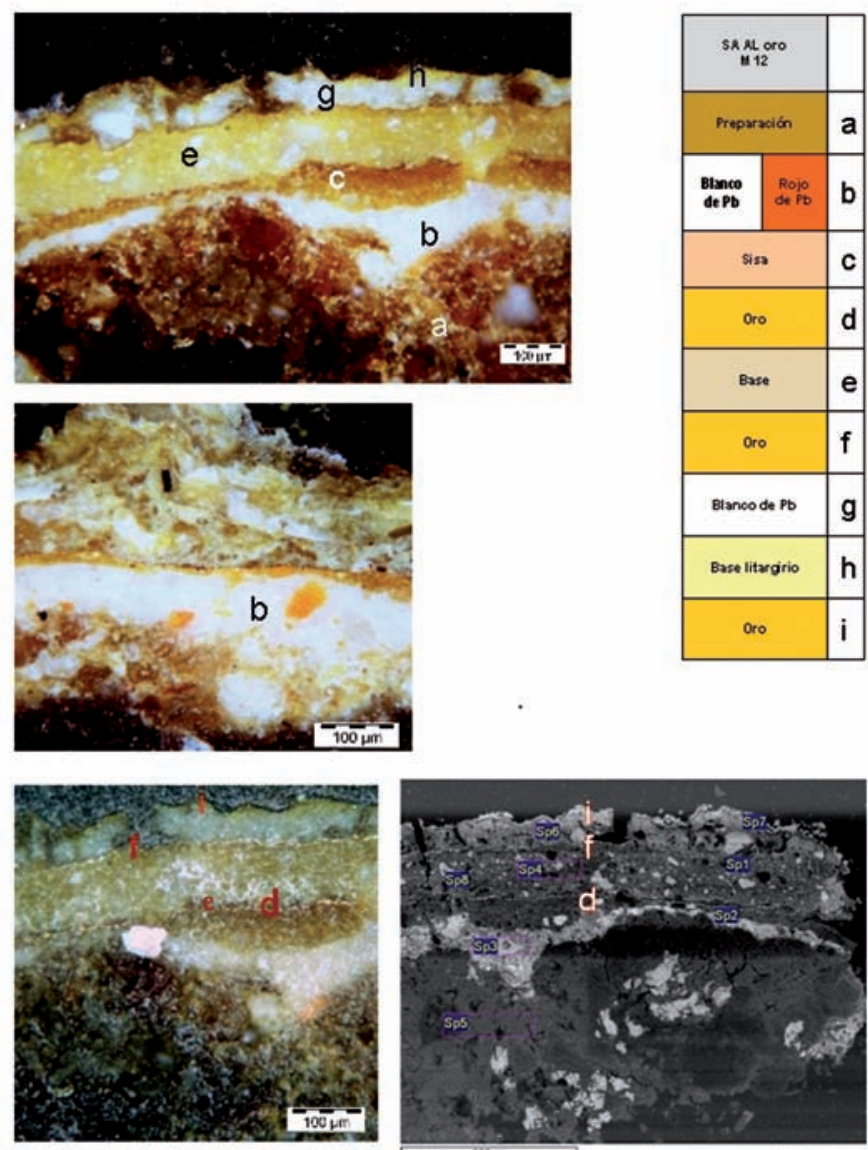

Fig. 4a. Primera parte del modelo de ficha para cada muestra. Se incluyen fotografías realizadas con microscopio de luz transmitida y reflejada, imagen de electrones retrodispersados realizadas en el microscopio electrónico de barrido y la correlación individualizada de los diferentes estratos que componen la muestra;

presencia de una serie de estratos idénticos en diferentes muestras, ha permitido establecer pautas de correspondencia y marcar hitos de datación cronológica relativa.

Para este trabajo se partió de la exhaustiva identificación de los materiales constitutivos de los diferentes estratos y de la técnica de ejecución utilizada en cada caso a partir de las 72 muestras estudiadas.

La presencia de distintas capas de dorado, como ya se ha dicho, aportan indicios claros para diferenciar unos repolicromados de otros. En algunas muestras se identificaron hasta 4 estratos diferentes de oro o dorados, como ocurre por ejemplo en la zona del fondo de los canecillos en la unión con el arrocabe y en las palmas de la parte superior de éste (Fig. 3). Por otra parte también se observó la presencia de varios niveles de un estrato blanco de considerable espesor y similar naturaleza presente, prácticamente, en todas las muestras.

\section{Alcázar Sevilla Fachada principal Alero M12 (canecillos)}
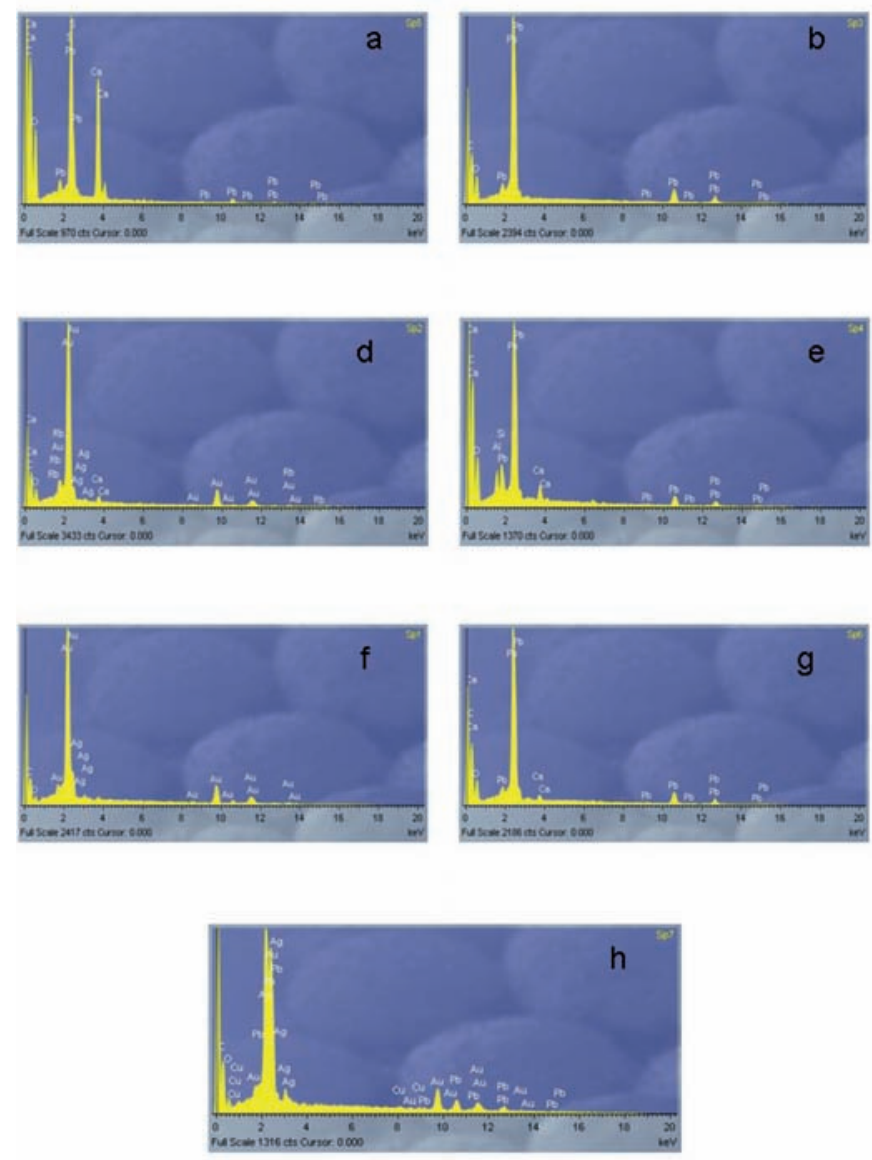

4b. Segunda parte de modelo de ficha donde se muestran los espectros analíticos obtenidos mediante microanálisis EDX

Para poder hacer una comparación más evidente, en primer lugar se trasladó la estratificación de las diferentes muestras a unas tablas con códigos de color previamente asignados a los diferentes pigmentos (ver modelo de ficha figuras. $4 \mathrm{a}$ y $4 \mathrm{~b}$ ). Estas tablas primero fueron individuales, para cada muestra y posteriormente se relacionaron agrupándolas por zonas. La correspondencia entre los diferentes niveles de las distintas muestras se hizo teniendo en cuenta las similitudes existentes, capas de dorado o preparación similares, y su datación cronológica relativa se plantea atendiendo a la propia cronología de los materiales identificados, dado que hay materiales que solo aparecen a partir de un determinado momento histórico.

Finalmente, se ha tratado de relacionar la secuencia de las diferentes actuaciones superpuestas, con la cronología de las operaciones de mantenimiento del monumento conocidas por referencias documentales. 


\section{Metodología seguida en el estudio de laboratorio de las policromías}

Investigación técnico-material. Orientada al conocimiento de los materiales y de los procesos de ejecución, es fundamental para la determinación del estado de conservación, para la identificación de las alteraciones y de las intervenciones que se han producido a lo largo de los años.

Las técnicas utilizadas han sido las siguientes:

- Preparación de estratigrafías para su estudio tanto en microscopía óptica como en SEM/EDX.

- Estudio mediante microscopía óptica.

- Microscopía electrónica de barrido (SEM) y (FESEM) con microanálisis mediante EDX.

- Identificación de fases mediante espectroscopía Raman y difracción de RX

- Identificación de materiales orgánicos mediante cromatografía de gases (GC) y cromatografía liquida de alta presión (HPLC).

\section{MATERIALES Y EJECUCIÓN}

\subsection{Materiales constitutivos}

Los materiales pictóricos que presenta la fachada principal del palacio de Pedro I se pueden dividir en dos grupos: El primero sería el de los materiales más antiguos, llamados históricos, que están, como es lógico, situados en capas más profundas, los cuales suelen ser de origen natural, aunque en algunos casos también son sintéticos. Además, como se ha dicho, presentan frecuentemente estratos de oro que, aunque no sean propiamente un pigmento, son una parte esencial en los acabados polícromos. Los pigmentos identificados en el alero principal se relacionan en la (Fig. 5).

Con respecto al material que aglutina y fija las capas pictóricas, el estudio cromatográfico indica que es aceite de linaza, en ocasiones combinado con resina de colofonia. Estos dos materiales tienen el inconveniente de producir un fuerte amarilleamiento, pero son indispensables para la consolidación de los pigmentos ya que los óleos, y el aceite de linaza en concreto, dan lugar a capas pictóricas muy estables y elásticas, por ser poco solubles y permeables. Este hecho se puede comprobar en las fotos de microscopía óptica (Fig. 6), ya que en bastantes policromías, sobre todo, las más impregnadas de aceites, las estratigrafías son muy consistentes. Este amarilleamiento es más evidente en los colores claros, especialmente en los blancos y azules, afectando al efecto cromático de la obra.

\begin{tabular}{|c|c|c|c|c|}
\hline \multirow{2}{*}{ PIGMENTO } & \multirow{2}{*}{ NATURALEZA } & \multirow{2}{*}{ COMPOSICIÓN QUÍMICA } & \multicolumn{2}{|c|}{ PERIODO DE UTILIZACIÓN } \\
\hline & & & $\mathrm{INIClO}$ & FINALIZACIÓN \\
\hline Blanco de plomo & $\mathrm{S}$ & $\mathrm{Pb}_{3}\left(\mathrm{CO}_{3}\right)_{2}(\mathrm{OH})_{2}$ & antigüedad & siglo $X X$ \\
\hline Blanco de España & $S$ & $\mathrm{CaCO}_{3}$ & antiqüedad & actual \\
\hline Barita & $\mathrm{M} / \mathrm{S}$ & $\mathrm{BaSO}_{4}$ & 1782 & sialo $\mathrm{XX}$ \\
\hline Cinabrio/Bermellón & M/S & $\mathrm{HgS}$ & antigüedad & siglo $X X$ \\
\hline Rojo de plomo/Minio & $\mathrm{S}$ & $\mathrm{Pb}_{3} \mathrm{O}_{4}$ & antiqüedad & siglo $X X$ \\
\hline Roio de óxidos de hierro & MS & $\mathrm{Fe}_{2} \mathrm{O}_{3}$ & antiaüedad & actual/Sialo XX \\
\hline $\begin{array}{l}\text { Lapislázuli } \\
\text { Azul ultramar }\end{array}$ & $\begin{array}{c}M \\
S\end{array}$ & $\mathrm{Na}_{3} \mathrm{Ca}\left(\mathrm{Al}_{3} \mathrm{Si}_{3} \mathrm{O}_{12}\right) \mathrm{S}$ & $\begin{array}{l}\text { antigüedad } \\
1828\end{array}$ & $\begin{array}{l}\text { siglo } X X \\
\text { actual }\end{array}$ \\
\hline $\begin{array}{l}\text { Azurita } \\
\text { Azurita sintética }\end{array}$ & $\begin{array}{l}M \\
\end{array}$ & $\mathrm{Cu}_{3}\left(\mathrm{CO}_{3}\right)_{2}(\mathrm{OH})_{2}$ & $\begin{array}{l}\text { antigüedad } \\
\text { s. XVII }\end{array}$ & $\begin{array}{l}\text { s. XVIIII } \\
\text { s. XIX }\end{array}$ \\
\hline Malaquita & $\overline{\mathrm{M}}$ & $\mathrm{Cu}_{2}\left(\mathrm{CO}_{3}\right)(\mathrm{OH})_{2}$ & antiqüedad & s. XVIII \\
\hline Verde de As v Cu & $\mathrm{S}$ & Arsenato de cobre & $?$ & $?$ \\
\hline Verde esmeralda & $S$ & $3 \mathrm{Cu}\left(\mathrm{AsO}_{2}\right)_{2} \mathrm{Cu}\left(\mathrm{CH}_{3} \mathrm{COO}\right)_{2}$ & 1814 & $1960 s$ \\
\hline Litarairio & $\mathrm{S}$ & $\mathrm{PbO}$ & antiaüedad & sialo $X X$ \\
\hline $\begin{array}{l}\text { Amarillo de plomo y } \\
\text { estaño }\end{array}$ & $S$ & $\mathrm{~Pb}_{2} \mathrm{SnO}_{4}$ & s. XIII & $\begin{array}{l}\text { mitad s. XVIII y } \\
>1940\end{array}$ \\
\hline Amarillo de cromo & $\mathrm{S}$ & $\mathrm{PbCrO}_{4} \mathrm{PbSO}_{4}$ & $\sim 1810$ & actual \\
\hline Nearo oraánico & $\mathrm{S} / \mathrm{M}$ & $\mathrm{C}$ & antiquedad & actual \\
\hline
\end{tabular}

Fig. 5. Tabla con la relación de pigmentos identificados en el alero, su naturaleza, composición química y periodos de utilización 


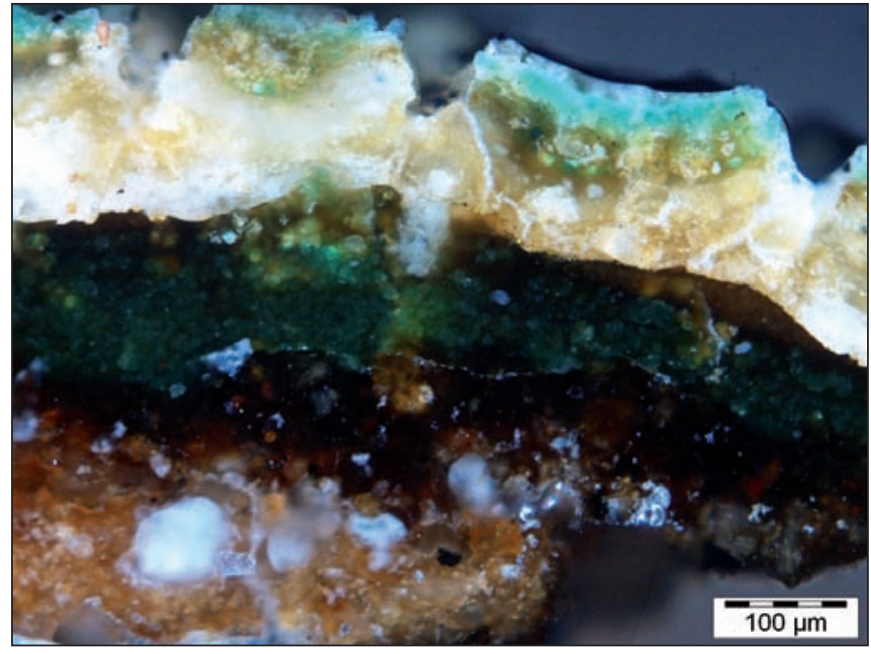

Fig. 6. Imagen de varios estratos impregnados de aceite. Se puede observar la modificación de color que provoca en los pigmentos y en las capas de preparación. Este efecto es más patente en el estrato de blanco de plomo

\subsection{Singularidades de los estratos pictóricos}

En la mayor parte de las muestras examinadas se ha podido observar una cantidad elevada de estratos. Se han identificado hasta quince, que podrían corresponder a nueve posibles policromías, en la mayoría de los casos con sus respectivas capas de base.

El material más empleado, como capa de terminación, es el oro, que aparece en un considerable número de las policromías identificadas. Los espectros analíticos ponen de manifiesto que estas capas de oro son bastante puras, sobre todo en los estratos profundos, y aunque en las últimas intervenciones doradas presentan aleación de plata y a veces cobre, estos metales están en muy pequeña proporción. La Real Academia de San Fernando debate en sus diferentes propuestas sobre la intervención de 1896 la conveniencia de utilizar oro puro o aleaciones, llegando a la conclusión de que se utilice oro de 20 quilates, como se había empleado en intervenciones anteriores, considerando que el tiempo matizaría su brillo ( Chávez, 2004, p. 247) (Fig. 7).

Por otra parte, hay que decir que algunos de los repolicromados van precedidos de una capa de base de color blanco, constituida por diversos materiales, que ha servido de referencia para correlacionar los estratos de las diferentes muestras. Con respecto a su composición, las más profundas, están formadas por yeso y, en algunos casos, por blanco de plomo con yeso. En un estrato intermedio se encuentra una capa muy característica que incluye junto al blanco de plomo una gran cantidad de nódulos de rojo de plomo (Fig. 8). El nivel blanco más superficial está constituido por calcita con blanco de plomo.

La penúltima capa blanca se puede considerar como una capa pictórica ya que está constituida solo por pigmento de blanco de plomo y sulfato de bario (barita). La presencia de barita permite hacer una aproximación a la fecha de ejecución ya que su empleo como pigmento, denominado blanco fijo, es propio de finales del siglo XVIII. Esta capa presenta un espesor que en la mayoría de los casos duplica o triplica el espesor de las capas de blanco de plomo de las otras policromías. En el transcurso del estudio de toda la fachada principal, se ha podido observar que está capa se presentan en un alto porcentaje de muestras, en torno a un $70 \%$. Esta circunstancia plantea diversas posibilidades. En un principio se pensó que pudiera aplicarse en torno a 1813, cuando el Alcázar sufrió un gran cambio en su policromías "padeciendo» un encalado muy generalizado (Chávez, 2004, p. 37), sin embargo

Fig. 7. (a) Imagen de SEM de electrones retrodispersados en la que se aprecia la presencia de dos estratigrafías con capas de oro (sp4 y sp1). (b) Espectro mediante EDX correspondiente al estrato profundo de oro (sp1) caracterizado por su gran pureza. (c) Espectro correspondiente al estrato superficial de oro (sp4) que contiene una mínina aleación de plata.
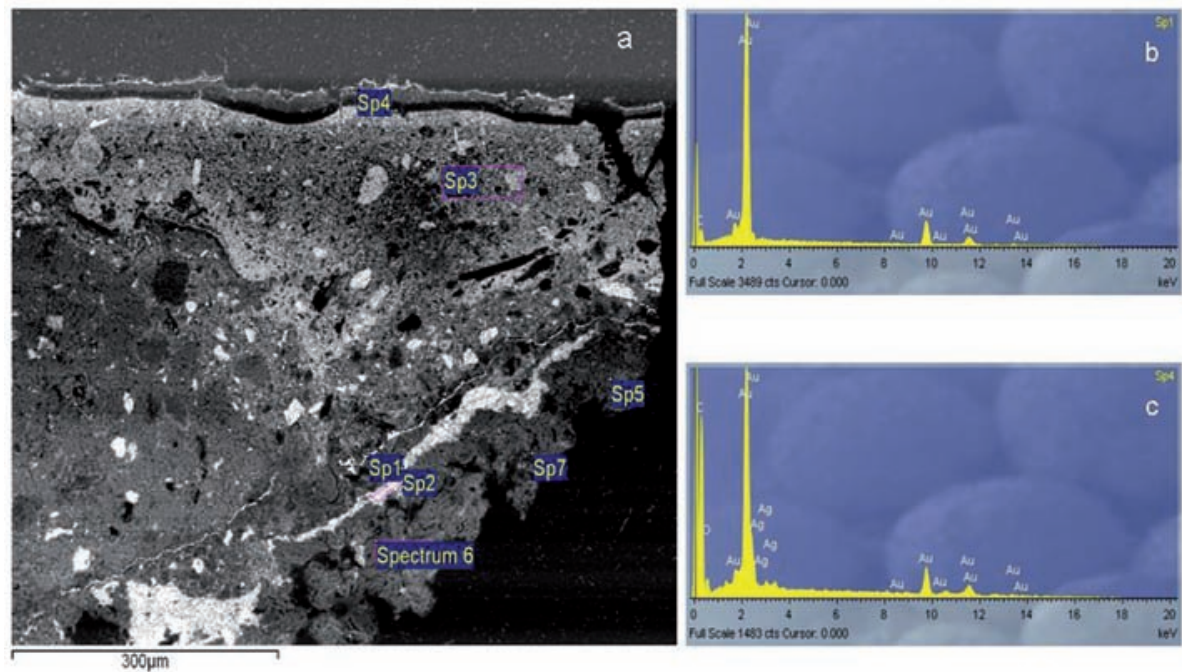


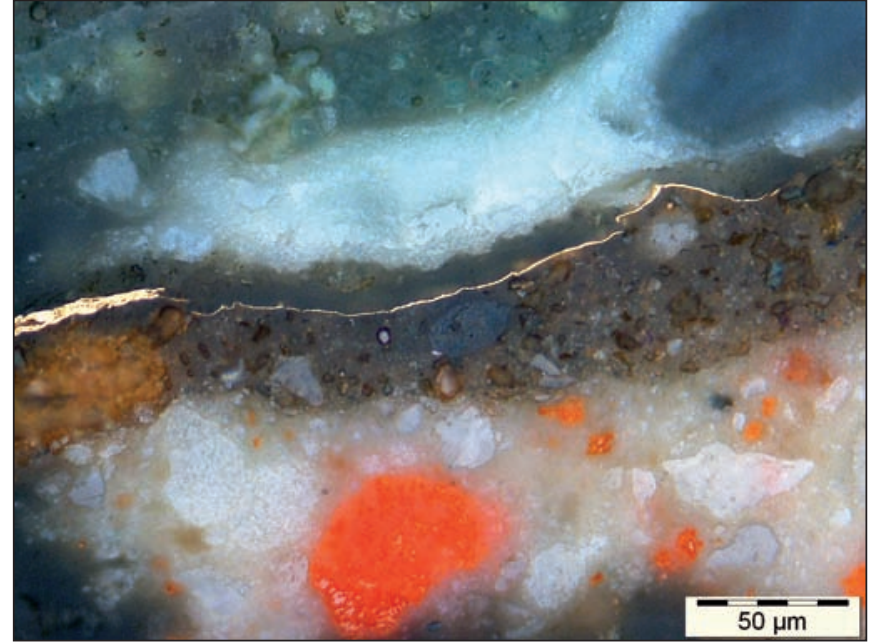

Fig. 8. Detalle de dos capas de base de blanco de plomo, la inferior incluye cristales de rojo de plomo y entre ambas destaca una capa de oro realizada sobre una capa de sisa

ninguno de los 12 documentos gráficos de la fachada conocidos (grabados, fotografías y dibujos), recopilados desde 1668 hasta 1936 (Almagro et al., 2009: pp. 16-22) permiten confirmar que esta capa blanca estuvieran en algún momento cambiando la policromía del alero.

Tras el estudio detallado de las muestras, y observando el estado de conservación, se puede considerar más probable que estas capas se aplicaran con la intención de preparar la superficie como capa de colmatación, empleándose para enrasar perdidas y servir de base a una nueva policromía, con una función similar a la de un estuco de nivelación. Lo que si está confirmado es que en la mayoría de las muestras, sirve de separación entre policromías más antiguas y las más recientes.

\section{CORRELACIONES}

Un estudio exhaustivo de los diferentes estratos ha permitido vincular entre si las capas pictóricas de las diferentes muestras, que ofrecemos por medio de las tablas de correlaciones adjuntas (Fig. 9, 10, 11, 12, 13, 14 y 15) que han constituido una herramienta fundamental para este trabajo. Dichas tablas corresponden a las muestras tomadas en sofitos, canecillos, cornisa, arrocabe, mocárabes y ménsulas.

El nivel A, que es el más antiguo, presenta restos de policromía que contienen una capa de preparación, de yeso y tierras, aglutinada con cola de origen proteico. A continuación se identifican pequeñas agrupaciones de cristales de rojo de plomo que debieron corresponderse con la capa de imprimación de la pintura original, sobre la que probablemente se aplicaran otros colores, en algunas zonas, pero de las que únicamente se conservan restos de rojo de cinabrio. Esta sucesión de estratos base de minio y cinabrio posteriormente, que ya se ha mencionado anteriormente permite obtener una tonalidad muy intensa con una relativa economía de medios y se repite en obras de similar cronología como por ejemplo en maderas policromadas de la Alhambra. Éstas preparaciones naranjas se daban cuando el color predominante eran los rojos (LópezPertínez, 2006, pp. 68-87). El hecho de que esta sucesión de estratos se haya conservado es indicativo de la estabilidad de dicha combinación, frente a la perdida de otros pigmentos, que seguramente se aplicaron, ya que la riqueza de las policromías sobre madera era considerable, como se puede comprobar, tanto en este caso, como en estudios similares.

\begin{tabular}{|c|c|c|c|c|c|c|c|c|c|}
\hline \multicolumn{10}{|c|}{ CORRELACIÓN ESTRATIGRÁFICA CANECILLOS } \\
\hline & M8 & M9 & \multicolumn{2}{|c|}{ M10 } & M11 & M20 & M21 & M22 & M23 \\
\hline \multirow{2}{*}{$\mathbf{A}$} & Preparación & & \multirow{2}{*}{\multicolumn{2}{|c|}{$\begin{array}{c}\text { Preparación } \\
\text { Rojo Pb }\end{array}$}} & Preparación & & & & \\
\hline & Rojo $\mathrm{Pb}$ & & & & Rojo $\mathrm{Pb}$ & & & & \\
\hline \multirow[b]{2}{*}{ B } & Blanco Pb/yeso & & & & & & & & \\
\hline & $\begin{array}{c}\text { Malaquita } \\
\text { natural }\end{array}$ & & & & & & & & \\
\hline \multirow{3}{*}{ C } & & & \multirow{2}{*}{\multicolumn{2}{|c|}{$\begin{array}{l}\text { Preparación } \\
\text { Blanco yeso/ Pb }\end{array}$}} & & & Preparación & & \\
\hline & & & & & & & Blanco Pb & & \\
\hline & & & $\begin{array}{c}\text { Malaquita } \\
\text { natural }\end{array}$ & $\begin{array}{l}\text { Amarillo de } \\
\mathrm{Pb}-\mathrm{Sn}\end{array}$ & & & Rojo Pb & & \\
\hline \multirow{4}{*}{ D } & & Preparación & \multicolumn{2}{|c|}{ Preparación } & Preparación & \multirow[t]{4}{*}{ Preparación } & & & Preparación \\
\hline & & \begin{tabular}{c|c}
$\begin{array}{c}\text { Blanco } \\
\text { Pb }\end{array}$ & Minio \\
\end{tabular} & & & \begin{tabular}{c|c}
$\begin{array}{c}\text { Blanco } \\
\text { Pb }\end{array}$ & Minio \\
\end{tabular} & & & & \begin{tabular}{c|c}
$\begin{array}{c}\text { Blanco } \\
\text { Pb }\end{array}$ & Minio \\
\end{tabular} \\
\hline & & Sisa & & & Sisa & & & & Sisa \\
\hline & & Oro & & & Oro & & & & Oro \\
\hline \multirow[b]{2}{*}{$\mathbf{E}$} & & Preparación & & & \multirow{2}{*}{$\begin{array}{l}\text { Azurita } \\
\text { sintética }\end{array}$} & & Preparación & & \\
\hline & & & & & & & Bermellón & & \\
\hline \multirow{2}{*}{$\mathbf{F}$} & Preparación & \multirow{2}{*}{$\begin{array}{l}\text { Capa pictórica } \mathrm{Pb} / \mathrm{Fe} \\
\text { aceite }\end{array}$} & \multicolumn{2}{|c|}{ Base $\mathrm{Pb} / \mathrm{Fe}$} & \multirow{2}{*}{$\begin{array}{c}\text { Capa pictórica } \mathrm{Pb} / \\
\text { aceite }\end{array}$} & \multirow{2}{*}{$\begin{array}{l}\text { Preparación } \\
\text { V. esmeralda }\end{array}$} & & & Base $\mathbf{P b} / \mathbf{F e}$ \\
\hline & V. esmeralda & & & & & & & & Oro \\
\hline \multirow{3}{*}{ G } & Blanca Pb & Blanca Pb & Bla & $\mathbf{P b}$ & Blanca $\mathrm{Pb} / \mathrm{Ca}$ & Blanca Pb/Ba & Blanca Pb & Blanca Pb & Blanca $\mathbf{P b} / \mathbf{B a}$ \\
\hline & \multirow[t]{2}{*}{ V. esmeralda } & $\begin{array}{l}\text { Base } \mathrm{Pb} / \mathrm{Fe} / \\
\text { litargirio }\end{array}$ & $\begin{aligned} \text { Bas } \\
\text { lite }\end{aligned}$ & $\begin{array}{l}\text { b/Fe/ } \\
\text { irio }\end{array}$ & $\begin{array}{l}\text { Base } \mathbf{P b} / \mathbf{F e} / \\
\text { litargirio }\end{array}$ & & \multirow[t]{2}{*}{ Bermellón } & $\begin{array}{c}\text { Base } \mathbf{P b} / \mathbf{F e} / \\
\text { litargirio }\end{array}$ & $\begin{array}{l}\mathrm{Base} \mathbf{P b} / \mathrm{Fe} / \\
\text { litargirio }\end{array}$ \\
\hline & & Oro & & & Oro & & & Oro & Oro \\
\hline
\end{tabular}

Fig. 9. Correlación de las estratigrafías pictóricas de los canecillos 


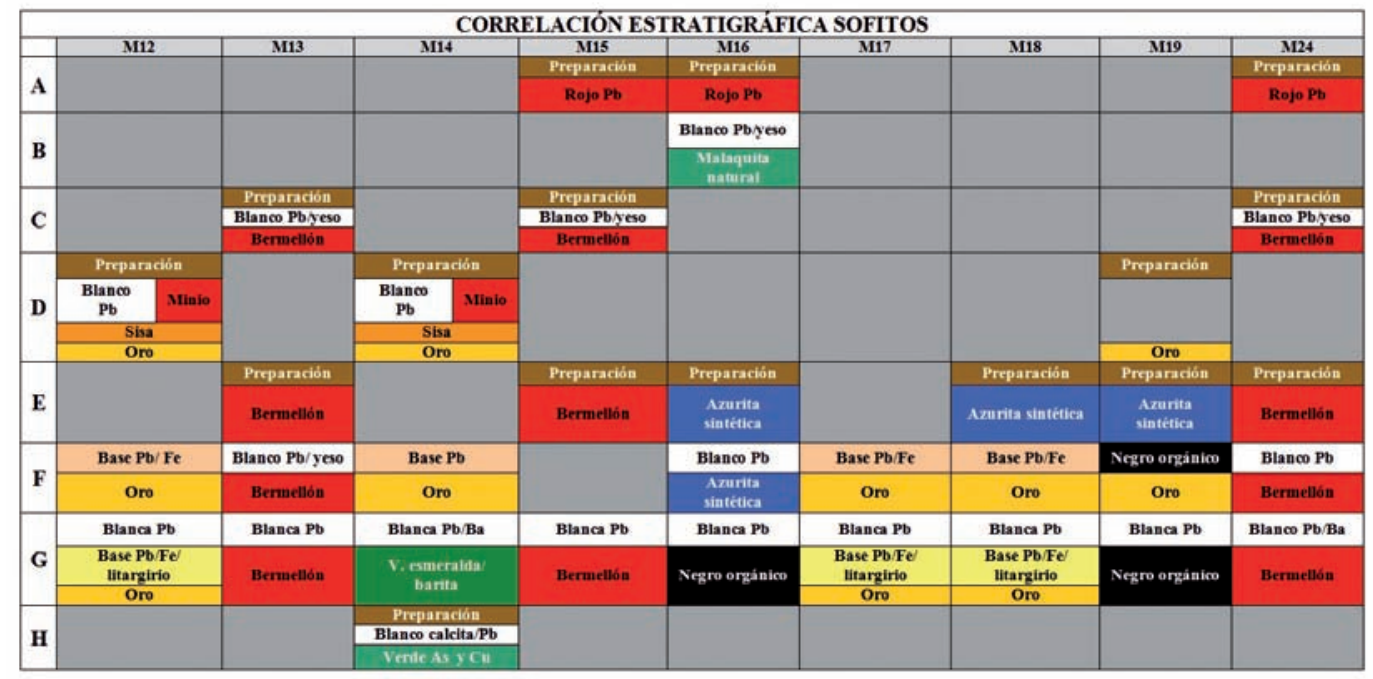

Fig. 10. Correlación de las estratigrafías pictóricas de los sofitos.

\begin{tabular}{|c|c|c|c|c|c|c|c|c|c|c|}
\hline \multirow{2}{*}{\multicolumn{11}{|c|}{ CORRELACIÓN ESTRATIGRÁFICA TABICA }} \\
\hline & & & & & & & & & & \\
\hline $\mathbf{A}$ & & $\begin{array}{l}\text { Proparackin } \\
\text { Rojo Pt } \\
\text { Cinabrio }\end{array}$ & & & & $\begin{array}{l}\text { Prepanacion } \\
\text { Rojo Pb } \\
\text { Cinabrio }\end{array}$ & & & & \\
\hline B & & & & \begin{tabular}{|c|c|} 
Blanco Pb Yeso \\
\end{tabular} & & $\begin{array}{c}\text { Blanco Pb Pesoo } \\
\begin{array}{c}\text { Azunta } \\
\text { natural }\end{array}\end{array}$ & & & & \\
\hline c & $\begin{array}{l}\text { Prepandón } \\
\text { Base Porecaca } \\
\text { Oro }\end{array}$ & & Oro & & & & & & & $\begin{array}{l}\text { Proparadón } \\
\text { Base } \mathrm{Pb} / \mathrm{Pb} / \mathrm{Fe}\end{array}$ \\
\hline D & & & $\begin{array}{c}\begin{array}{c}\text { Preparación } \\
\text { Blaneo } \\
\text { Po }\end{array} \\
\text { Sisa } \\
\text { Oro } \\
\end{array}$ & & & & & & & \\
\hline E & & & & $\begin{array}{l}\text { Prepanadian } \\
\text { Azurita } \\
\text { sintétea }\end{array}$ & $\begin{array}{l}\text { Prepparacion } \\
\text { Azurtita } \\
\text { intética }\end{array}$ & & $\begin{array}{c}\text { Proparadón } \\
\text { Negero } \\
\text { orgeinico }\end{array}$ & & Preparadian & \\
\hline & Proparadón & Prepanacía & Base Pb/Fe & Base Pb/Fe & & Preparación & Base $\mathrm{Pb} / \mathrm{Fe}$ & Base PbFe & & Base Pb/Fe \\
\hline$F$ & v. amerahts & Bermellón & Oro & Oro & & v. smersita & oro & Oro & & Oro \\
\hline G & & & & & & & & & & \\
\hline 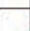 & Blanca Pbica & Blanca Pbica & Blance Pbica & Blana Pbica & Blanca Pbica & Blanca Pb/Ca & Blanca Pb & Blanca Pbica & Blanca Pb & Blanca $\mathrm{Pb} / \mathrm{Ca}$ \\
\hline H & verile As icu & Bermestibn & Base Pbicr & 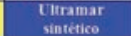 & Negro & Bermellón & Bermetlion & Base Pbicr & Base Paicr & Base Pbicr \\
\hline & & & Oro & Oro & өгz̧inico & & & Oro & Oro & Oro \\
\hline I & & & & & & $\begin{array}{l}\text { Bianca Pbica } \\
\text { Verde As Ca }\end{array}$ & & & & \\
\hline
\end{tabular}

Fig. 11. Correlación de las estratigrafías pictóricas de la tabica.

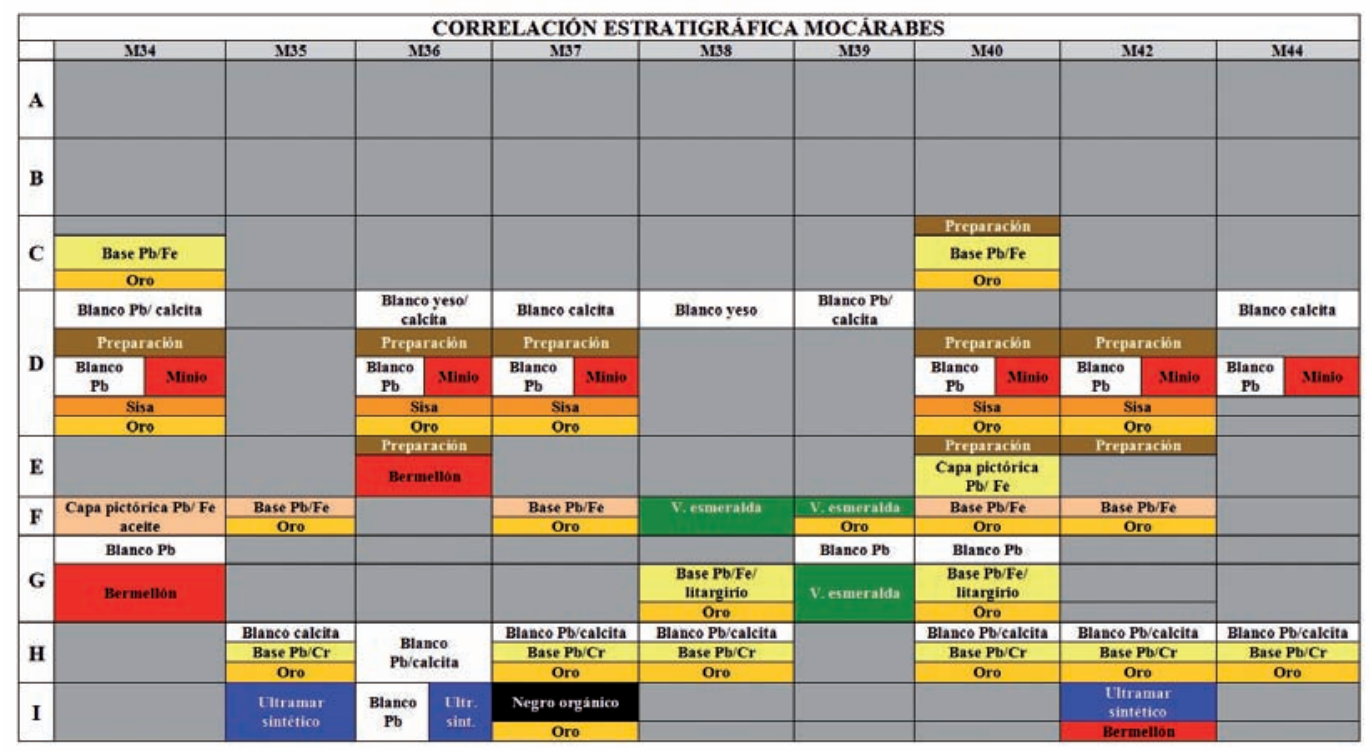

Fig. 12. Correlación de las estratigrafías pictóricas de los mocárabes. 


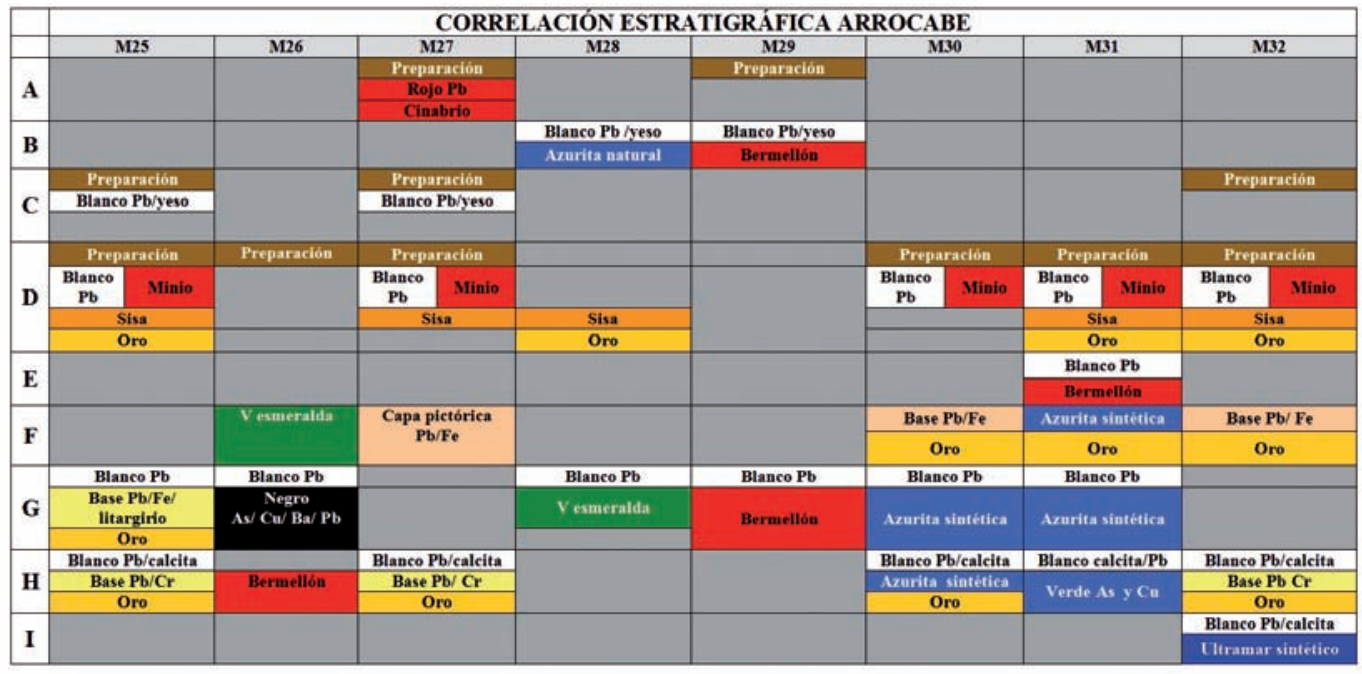

Fig. 13. Correlación de las estratigrafías pictóricas del arrocabe.

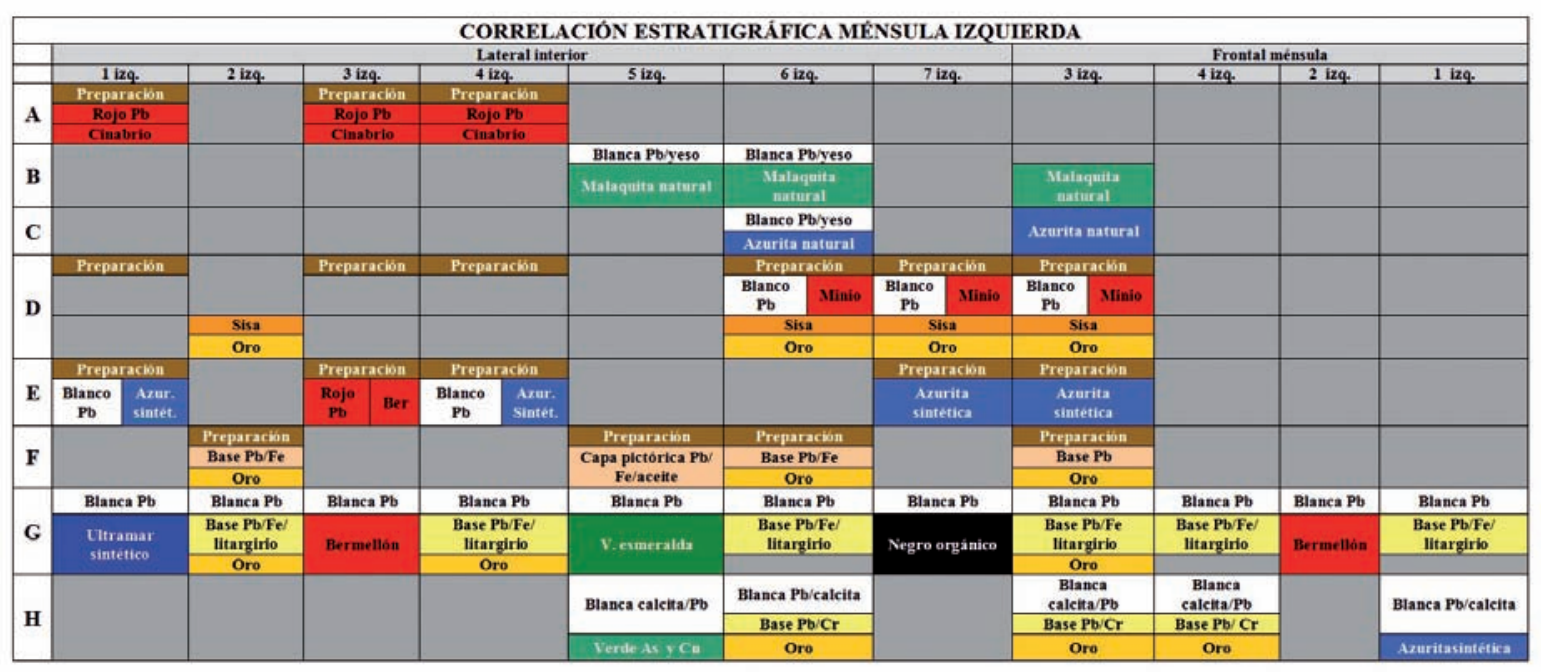

Fig. 14. Correlación de las estratigrafías pictóricas de la ménsula

\begin{tabular}{|c|c|c|c|c|c|c|c|}
\hline \multicolumn{8}{|c|}{ CORRELACIÓN ESTRATIGRÁFICA MÉNSULA DERECHA } \\
\hline \multirow{4}{*}{$\mathbf{A}$} & & M1 & M2 & M3 & M5 & M6 & M7 \\
\hline & & aración & Preparación & Preparación & & & \\
\hline & & jo $\mathrm{Pb}$ & $\mathrm{Rojo} \mathrm{Pb}$ & \multirow{2}{*}{ Rojo Pb } & & & \\
\hline & \multicolumn{2}{|c|}{$\begin{array}{l}\text { Cinabrio } \\
\text { Blanca base }\end{array}$} & Cinabrio & & & & \\
\hline \multirow{3}{*}{ B } & & ca base & & & & & \\
\hline & \multicolumn{2}{|c|}{ Rojo $\mathrm{Pb}$} & & & & & \\
\hline & \multicolumn{2}{|c|}{ Cinabrio } & & & & & \\
\hline \multicolumn{8}{|l|}{ C } \\
\hline \multicolumn{8}{|l|}{ D } \\
\hline \multirow{2}{*}{$\mathbf{E}$} & \multicolumn{2}{|c|}{ Preparación } & & & & & \\
\hline & \multicolumn{2}{|c|}{ Axurita sintética } & & & & & \\
\hline \multirow{2}{*}{$\mathbf{F}$} & & & Base & & & & \\
\hline & & & Oro & & & & \\
\hline \multirow{3}{*}{ G } & & aca Pb & Blanca Pb & Blanca $\mathrm{Pb}$ & Blanca Pb & Blanca Pb & Blanca $\mathrm{Pb}$ \\
\hline & \multicolumn{2}{|c|}{ Base litargirio } & \multirow{2}{*}{ V. esmeralda } & \multirow{2}{*}{ Azurita sintética } & V. esmeralda & & V. emmeralda \\
\hline & & Dro & & & Eltramar sintético & & Oro \\
\hline \multirow{3}{*}{$\mathbf{H}$} & & aración & Preparación & Preparación & \multirow{3}{*}{ Bermellön } & Prepanación & Preparación \\
\hline & & ca base & Blanco base $\mathrm{Pb} / \mathrm{Ba}$ & Blanca base & & Blanca base & Blanca base \\
\hline & $\begin{array}{c}\text { Rojo } \\
\mathrm{Pb}\end{array}$ & Bermellón & Bermellón & Azurta sintetica & & Bermellón & Vltramar sintético \\
\hline \multirow{2}{*}{ I } & & & Base $\mathrm{Cr}$ & & & Base $\mathrm{Cr}$ & \\
\hline & & & Oro & & & Oro & \\
\hline
\end{tabular}

Fig. 15. Correlación de las estratigrafías pictóricas de la ménsula derecha. 


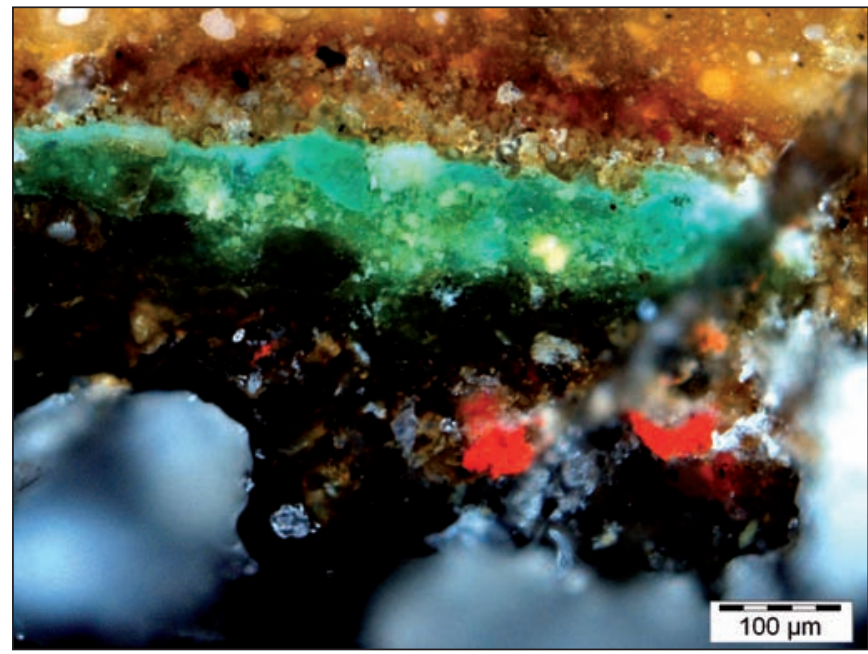

Fig. 16. Estrato de preparación constituido por yeso perteneciente a la primera policromía con restos de rojo de plomo. La siguiente capa corresponde a malaquita natural con amarillo de plomo y estaño, seguida de otra capa preparatoria

En la siguiente policromía, B, se observa una mayor variedad de pigmentos. Se incluye el uso de gran cantidad de verde de malaquita natural y azurita también natural además de rojo bermellón (Fig. 16).

El nivel de policromía $\mathrm{C}$ está constituido por oro, rojo de plomo, bermellón, azurita y malaquita naturales. La malaquita, en los canecillos, está mezclada con amarillo de plomo y estaño. Los restos de oro se encuentran localizados en la zona de mocárabes y en la tabica. En los mocárabes solo existen restos de esta policromía dorada hecho que es muy significativo ya que coincide con la situación que actualmente encontramos en esta zona, en la que la mayor parte de la superficie está dorada bien con estratos de oro o con la aplicación de capas amarillas que imitan el oro. En este nivel de policromía, el oro presenta una pequeñísima cantidad de plata.

La policromía D está constituida por un dorado generalizado muy peculiar, ya que se efectuó sobre un barniz al que se añadieron una amplia variedad de restos de

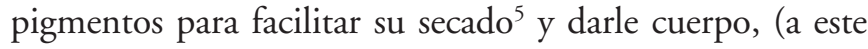
procedimiento tradicionalmente se llamaba sisa ${ }^{6}$ ). Esta policromía tiene la singularidad de estar aplicada sobre una base preparada con una mezcla de blanco de plomo y minio y ha sido observada en todas las zonas seleccionadas, mocárabes, arrocabe, cornisa, ménsula, canecillos y sofitos. Por otra parte, no existen indicios que confirmen el uso de

${ }^{5}$ Los pigmentos que contienen en su composición elementos metálicos, como los de plomo o cobalto que favorecen el secado de los aceites, se añadían a este tipo de barnices para acelerar el proceso de polimerización de los mismos.

${ }^{6}$ Según Ana Calvo (2003, p. 206), Sisa: barniz a base de aceite de linaza con pigmentos finamente molidos, generalmente derivados de plomo y cobre que aceleran el secado y le confieren una calidad mordiente, empleado para asentar el oro.

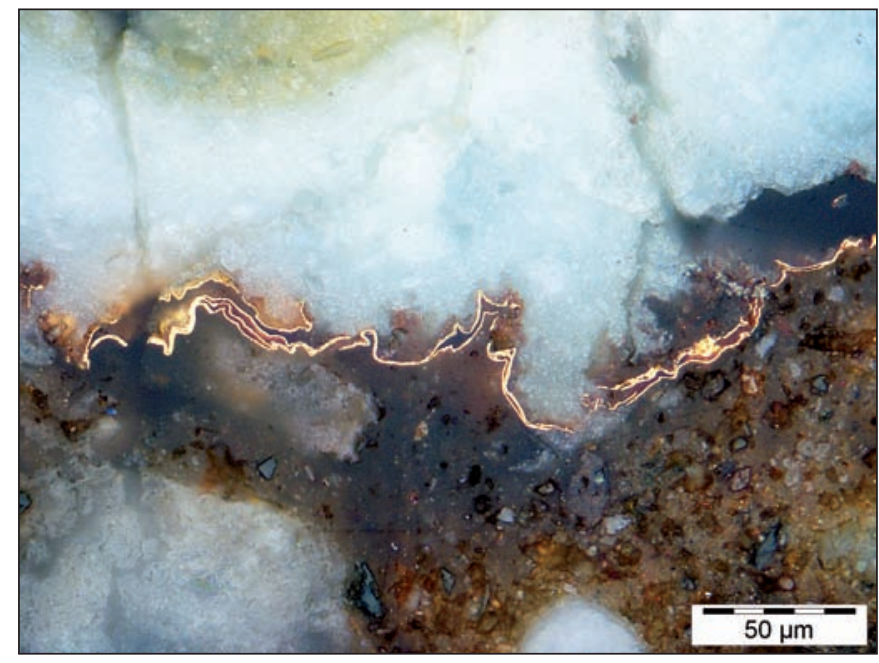

Fig. 17. Capa de sisa (barniz con pigmentos) con su respectiva capa de oro

otros acabados de color en esta policromía ya que no se han detectado restos de pigmentos que puedan asociarse a la misma. En ese caso cabría pensar que, en este momento, el alero estuviera dorado en su totalidad lo que supondría un considerable cambio respecto a situaciones precedentes (Fig. 17).

En la piedra de la portada se han identificado restos de color, aplicados sobre una base de blanco de plomo con minio, que pueden relacionarse claramente con estos estratos. Los pigmentos identificados sobre esta preparación, en la piedra, son: bermellón (en el fondo del escudo del castillo) azul (en el fondo del león) y oro y negro (en el escudo de la banda) (Fig. 18).

La policromía E, probablemente, se realizó como consecuencia de la reacción provocada por el dorado generali-

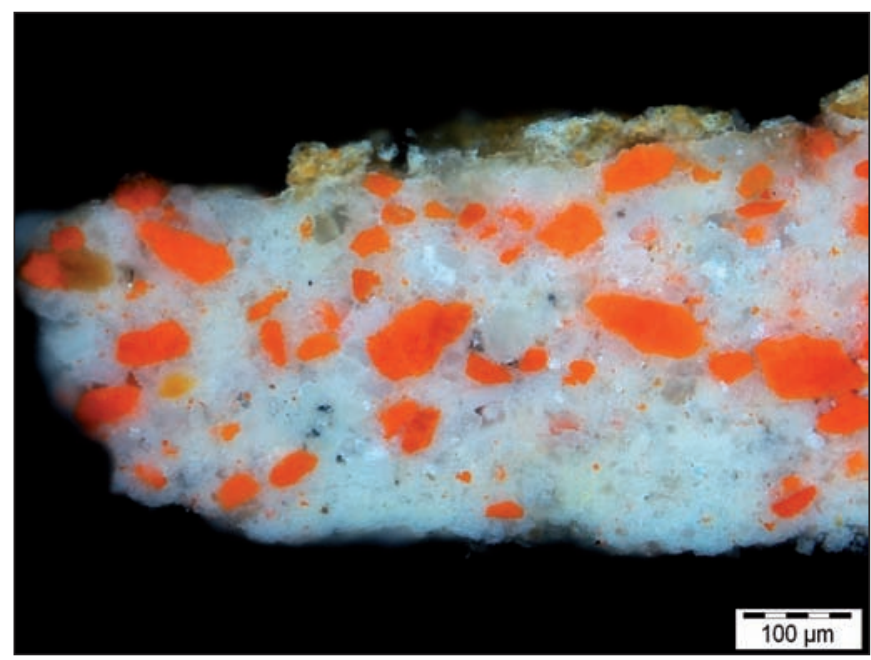

Fig. 18. Capa de base preparatoria de policromía de oro realizada sobre soporte de piedra. Está constituida por blanco de plomo y rojo de plomo 


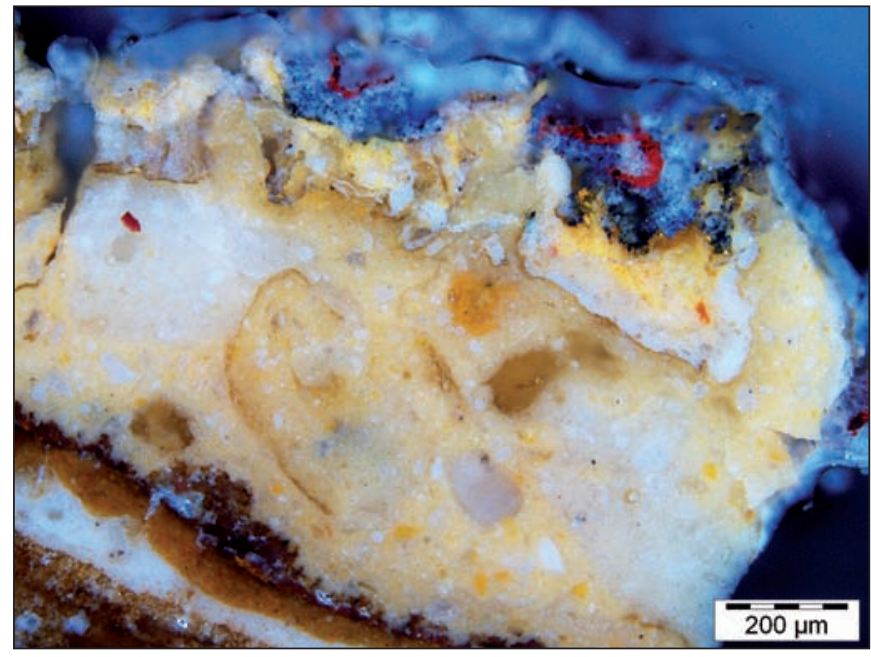

Fig. 19. Capas amarillas de base, preparatorias del oro, realizadas con la misma técnica que las capas de corlas. Se superpone una capa de azul ultramar que termina con trazas rojas pertenecientes a un dibujo

zado de la anterior, y en ella se emplea una mayor variedad de pigmentos y, por el contrario, no se detectan capas de oro. Se trata claramente de otra policromía y no de detalles aplicados sobre el oro, ya que los estratos de color se aplicaron sobre una capa de preparación que debió ocultar estratos precedentes. Los pigmentos identificados son rojo bermellón, azurita, negro. La modificación del aspecto cromático, respecto a la intervención anterior, debió ser muy evidente, aunque no se puede descartar, que se mantuviera a la vista parte de la base dorada previa, por lo que, indudablemente, en ese caso, el cambio, aún siendo importante, no sería total. La semejanza con respecto a la situación actual sería mayor en este último nivel que en la precedente ya que se alternan los dorados con zonas de color.

La policromía $\mathrm{F}$ repite el estrato dorado en gran parte de los motivos decorativos, aunque en este caso se sustituye la preparación del dorado a la sisa por una capa de blanco de plomo muy amarilleada por la presencia de aceites y resinas con hierro y probablemente litargirio, que es un óxido de plomo de color amarillo utilizado como secativo, pero también para dar a la base del oro una tonalidad amarilla que disimularía las posibles faltas de metal que se produjeran. Se ha identificado este acabado en todas las zonas estudiadas: canecillos, mocárabes, cornisa y ménsulas, se han conservado, además del dorado, restos de pigmentos, concretamente blanco de plomo, rojo bermellón, azurita y verde esmeralda un verde sintético, constituido por cobre y arsénico. Este pigmento tiene su primera referencia de uso en 1814, por lo que ésta policromía debe situarse en un momento cronológicamente posterior a dicha fecha. En esta policromía volvemos a encontrar una

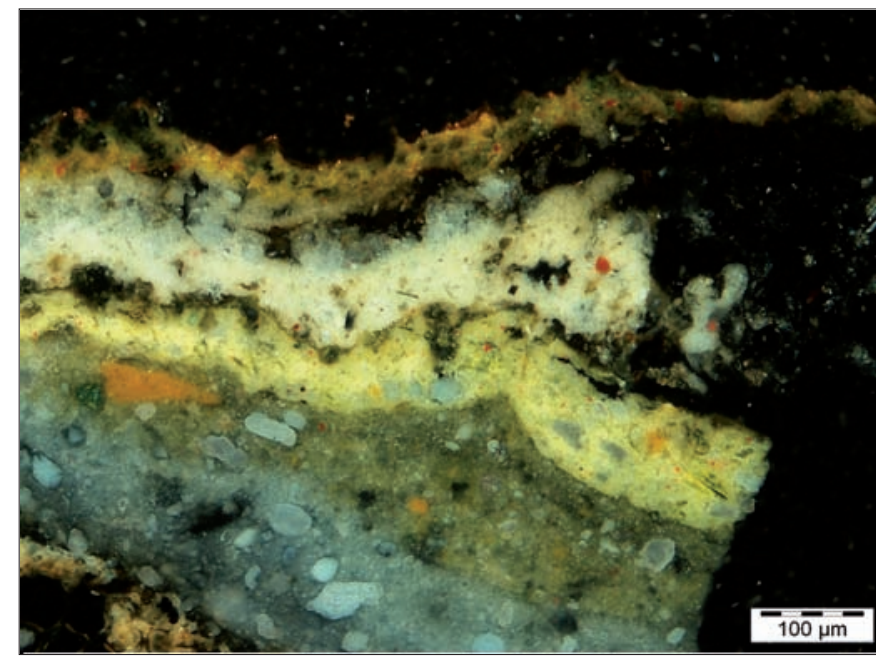

Fig. 20. Capas amarillas que imitan el oro en la sexta, séptima y octava policromías (esta última con cromo)

superficie mayoritariamente dorada como en el caso de la policromía D.

La policromía $\mathrm{G}$ se aplica sobre una capa de base muy característica de blanco de plomo y barita que se ha identificado en numerosas muestras estudiadas. Las imágenes tomadas con microscopía electrónica de barrido (FESEM) de esta capa muestran que la textura de los cristales presentan características similares en todas las zonas, por lo que puede deducirse que corresponde a un mismo momento de fabricación del pigmento. Como ya se ha dicho, esta capa de blanco de plomo puede relacionarse con la intervención que se hace sobre las ménsulas en 1898, en la que se repone parte de las mismas, ya que en las muestras tomadas correspondientes a ésta zona es el primer estrato identificado en un considerable número de ellas, concretamente las tomadas del frontal y del arranque de las mismas. Sobre esta capa, probablemente realizada como una base de nivelación, se aplicaron en algunas zonas pigmentos: verde esmeralda, bermellón, azurita artificial, ultramar artificial y negro orgánico y en otras dorados al mixtión, en este caso preparados con blanco de plomo, hierro y litargirio (Fig. 19). Esta capa amarilla en algunas zonas no se cubrió completamente de oro actuando como una corla, como se puede comprobar en los canecillos y en los mocárabes (Fig. 20).

El nivel $\mathrm{H}$ está constituido principalmente por una capa de base preparatoria del dorado que en esta policromía está compuesta por blanco de plomo y amarillo de cromo. Esta capa de base tiene la misma función preparatoria que la de la policromía anterior pero cambiando el hierro y litargirio por amarillo de cromo (Figs. 19 y 20). 
En los sofitos esta intervención se presenta solo en una muestra de color verde. Puede que en esta intervención no se cubriera completamente la policromía anterior por encontrarse en buen estado de conservación.

En la tabica y en los mocárabes la base de cromo se presenta en la mayor parte de las muestras estudiadas, exceptuando la que están formadas por blanco de plomo y calcio y los verdes sintéticos de arsénico y cobre. Como se ha mencionado en el nivel $\mathrm{F}$ se aplicó terminación dorada que en esta ocasión se realizó con base de cromo.

La ménsula derecha presenta variantes ya que se identifica un nivel más entre el dorado realizado con litargirio y el realizado con cromo. Esta policromía se presenta completa (preparación, base y pigmento) y en ella se ha identificado rojo de plomo mezclado con bermellón, bermellón solo, azurita artificial, azul ultramar artificial y verde sintético de arsénico y cobre.

La policromía I es la última encontrada y puede corresponder con actuaciones puntuales. Se encuentra en el arrocabe y los mocárabes. Como interpretación general podría indicar retoques en partes dañadas, pero por ahora no se puede dar esta lectura, pues ocultan zonas en perfecto estado de conservación como sucede en las muestras M30, M31 y M32 del arrocabe que pertenece a las bandas inferiores a los mocárabes (Fig. 12). En las muestras M35, M36, M37 y M42 que corresponden a la parte alta de los mocárabes (Fig.12) si pueden relacionarse con dibujos existentes encima de la policromía dorada como puede observarse en la (Fig. 19).

\section{REVISIÓN DOCUMENTAL}

A la vista del estudio de materiales y de las correlaciones estratigráficas se puede decir que actualmente los colores originales de la fachada del Palacio de Pedro I han desaparecido o están ocultos en su totalidad, ya que las intervenciones en las policromías se sucedieron a lo largo de los años. Las primeras referencias que se tienen de grandes modificaciones en la fachada del Palacio son las realizadas durante el reinado de los Reyes Católicos. A esta época pertenece la construcción de las arquerías superiores de las fachadas laterales de la portada principal (Manzano, 1983, pp. 30-31). Estas intervenciones, como es lógico, debieron repercutir considerablemente en las policromías y cabe pensar que se llevaran a cabo en toda la fachada.

En 1542 se procedió al arreglo de los tejados que caen sobre la fachada principal y a la reparación del alero de esta portada (Marín, 1990, p.164).
Pocos años después, en 1560, se trabaja en la fachada del Palacio sobre todo en el alero de la portada y en el de las fachadas laterales (Marín, 1990, p. 223).

Coincidiendo con las obras de las salas que asoman a la fachada, en 1584 se realizan también las de la fachada principal. Estas obras concluyeron el 10 de septiembre de 1586 (Marín, 1990, p. 226). La misma intervención está referenciada por (Gestoso, 1899, p. 58) pero en este caso solo se especifican las fachadas laterales.

A partir de estas fechas no se han encontrado referencias concretas a las policromías de la fachada del Palacio, se piensa, que con motivo de la anunciada visita a Sevilla de Felipe IV en 1624 se suscitaron gran cantidad de intervenciones, que fueron dirigidas por el maestro de obras Vermondo Resta, bajo la alcaldía del Conde-Duque de Olivares, aunque no se ha encontrado constancia de ellas (Marín, 1990, p. 419).

De un informe de 27 de marzo de 1805 escrito por D. Manuel Zintora se concluye que se iban a realizar actuaciones solo en las galerías superiores del Patio pero se puede comprobar que en menos de un año se efectúan un gran volumen de obras que afectaron a la fachada principal. (Chávez, 2004, pp. 32 y 34).

En mayo de 1841 D. Juan Manuel Caballero se encargará de las obras coincidiendo con un periodo en que se prepara el Alcázar para recibir a los duques de Montpensier, siendo una época en la que se llevará a cabo gran cantidad de arreglos para acomodar el edificio.

En 1846 existen referencias de varios informes detallados en relación con las obras apremiantes que necesitaba la totalidad del Palacio. Con respecto a la fachada principal se señala que está muy deteriorada y que necesita reponer seis varas de dibujo árabe, doce calados árabes nuevos, estucar doscientas cuarentas varas de sus paredes y limpiar todo el árabe que está encalado» (Chávez, 2004, p.208).

En 1847 en un documento de la administración de los Reales Alcázares se expone que el Pórtico general está finalizado de albañiles y que solo falta colocar algunas tablas talladas y pintarlo como estaba antiguamente (Chávez, 2004, p. 207). Según las críticas realizadas en el informe de Gómez Otero en 1894, al parecer, estas tablas no fueron realizadas con mucho cuidado. Las obras, finalizadas en la primera quincena de abril de 1848, descubrieron una fachada que había sido repintada y que había devuelto el color a las zonas originales que se mostraban cubiertas con un brillo excesivo, según el juicio desfavorable que realizó el pintor de cámara Valentín Carderera quien abiertamente manifestó su desacuerdo (Chávez, 2004, p. 214). 
En 1857 D. José Domínguez Bécquer indica, al hacer una relación de intervenciones, que continua con los trabajos de la fachada principal y que es muy complicada por su gran cantidad de adornos (Chávez, 2004, pp. 257259).

Hasta agosto de 1894, fecha de un informe de D. José Gómez Otero, no se han encontrado nuevas referencias a las policromías de la fachada. Este informe se centra, sobre todo, en el estado de los grandes soportes o ménsulas que sustentan por los extremos el alero de la portada. Además, en él se queja de la mala intervención que se llevó a cabo en 1848 cuando se abordó el problema de la pudrición mediante el empleo de un forrado de láminas de plomo que, al separarse, en vez de resguardar se convirtieron en un depósito de humedad pegado a la madera. (Chávez, 2004, p. 266).

En julio de 1895 se pide consulta a intendencia general respecto a los dorados con oro y colores que se deben emplear en la fachada. Tras gran cantidad de argumentaciones en diciembre de 1897, según consta en el informe redactado por Gómez Otero, la Real Academia de San Fernando autoriza dorar la fachada principal y realizar esta labor al completo, no solo las piezas nuevas como se pensó en un principio. Se propone utilizar oro puro, aunque quede muy brillante, dejando que sea la intemperie quién matice ese brillo. En junio de 1898 se termina la pintura y dorado en el piso alto y se aconseja seguir esta actuación en el piso bajo (Chávez, 2004, pp. 168-266).

La preocupación por la conservación del Alcázar y, más concretamente, sobre la de su policromía ha permanecido a lo largo de los años. Rafael Cómez al señalar la actitud academicista de la Real Academia de San Fernando, que promueve armonizar los tonos de los colores con que se interviene en 1898 con los ya deslustrados de intervenciones anteriores, nos dice con respecto a esta actuación: "El horror a la policromía, a los vivos colores que aún pervivian en el edificio movió a los académicos a presentar una situación intermedia que no molestase a nadie alegando el desconocimiento cierto de las técnicas pictóricas medievales empleadas originalmente, y aconsejando la armonización de tonos con el resto de la fachada, con lo cual se perdería para siempre los restos existente de aquella resplandeciente fachada en oro y azul alabada por Rodrigo Caro." (Cómez, 2006, p. 110) ${ }^{7}$.

${ }^{7}$ Rodrigo Caro expone estos datos en 1634 en su libro: Antigüedad y principado de la Ilustrísima ciudad de Sevilla y corografía de su convento jurídico o antigua chancillería.

\section{CONCLUSIONES}

$\mathrm{El}$ interés principal que presentan las correlaciones que se han elaborado es, el de poder llegar a establecer aproximaciones respecto a la evolución cromática de la fachada del Palacio de Pedro I y además poder relacionarlas con las referencias documentales existentes, procedentes de archivos y de los textos de escritores que vivieron esos momentos. Esto, evidentemente, hay que hacerlo con todas las reservas posibles, ya que es difícil establecer con absoluta certeza la equivalencia entre los estratos identificados y las intervenciones descritas en los textos.

El estudio de materiales reporta algunas conclusiones respecto a las policromías que permiten situar cronológicamente algunos estratos, tanto por la tradición de su empleo en un periodo determinado, como, por ejemplo, la utilización de dorados realizados con sisa, típicos de la pintura española de los siglos de oro (Bruquetas, 2002, p. 398), como también por el hecho de que su utilización se inicie en una fecha concreta. Así, por ejemplo, el empleo de verde esmeralda, que como ya se ha dicho su primera referencia de uso es de 1814 (Eastaugh et al., 2004, p. 155), es indicativo de que los estratos que contengan este pigmento no pueden ser anteriores a dicha fecha. Igualmente ocurre con el azul ultramar sintético, que comienza a emplearse en 1828 (Matteini, 2008, p. 56).

De este modo, la policromía $\mathrm{D}$, cuyo dorado se aplica a la sisa, como se ha dicho, puede relacionarse con intervenciones de los siglos XVII o a lo sumo XVIII ya que se trata de un procedimiento tradicionalmente utilizado en la pintura española de estos siglos.

Como consecuencia de ello la policromía precedente (C) corresponderían a alguna de las intervenciones referenciadas en documentos de archivo correspondientes al siglo XVI. Referenciadas están las de 1542, 1560 y 1584 aunque no hay elementos que permitan asociarlas concretamente a ninguna. El empleo de azurita y malaquita natural en estos niveles de policromía, confirma que se trata de una intervención relacionada con esas fechas (Fig.21 y 16), ya que en el siglo XVII comienza a emplearse la azurita artificial, (Fig. 22) aunque según Harley existen referencias de recetas anteriores a 1600 (Harley, 1982, p 48)

La policromía B puede relacionarse con intervenciones que se realizaran en el siglo XV. La utilización en este nivel de gran cantidad de malaquita natural y azurita también natural lleva a pensar que nos encontramos antes una intervención con pigmentos originales o muy cercanos en el tiempo a las policromías originales.

Los restos de la primera policromía conservada $\mathrm{A}$, que presentan preparaciones tradicionales de yeso y tierras, 


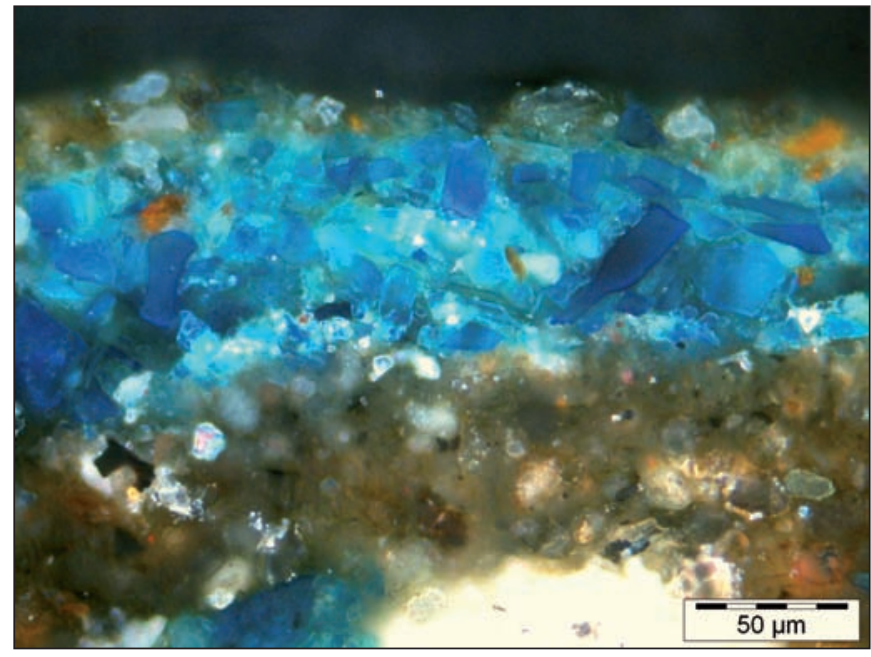

Fig. 21. Estrato interno de azurita natural sobre un nivel de preparación impregnado de aceite. Se caracteriza por estar formada por cristales de diferentes tamaños y con formas angulosas

sobre los que se aplicó una base de rojo de plomo podrían considerarse restos de la policromía original. Muy probablemente también se utilizara pigmento azul de azurita y oro como indica Rodrigo Caro en 1634 (Cómez 2006, p. 110). Desgraciadamente no se conservan restos de estos materiales pero su uso, dada la riqueza de las policromías sobre madera en estos momentos lo hace muy probable.

Estos niveles interiores presentan amplias lagunas que pueden estar motivadas por las malas condiciones de conservación, y por ser una zona muy expuesta a la intemperie. Además están referenciados varios incendios que podrían haber afectado a estos niveles de policromías, aunque no existen indicios de que el incendio afectara directamente a las maderas del alero, evidentemente si debieron estar sometidas a una elevada temperatura que es una de las causas mas directas en el deterioro de las policromías.

La policromía E está constituida por gran cantidad de azurita sintética, bermellón y negro orgánico. Es muy significativo que en este nivel no aparezca ninguna muestra que contenga oro. Cabe pensar que se respetara el oro del nivel anterior en los estratos que lo conservaran, o se realizará esta intervención como consecuencia de un cambio de gusto con respecto a los dorados. El hecho de utilizar en esta actuación azurita sintética masivamente, descubierta en el siglo XVII nos lleva a pensar que esta intervención puede asociarse a 1612 o 1624 fechas en las que se llevaron a cabo obras para recibir las visitas de Felipe III y Felipe IV.

En la policromía $\mathrm{F}$ se ha identificado verde esmeralda en gran parte de las muestras estudiadas. Dada la fecha de síntesis de este pigmento, esta intervención debe situarse

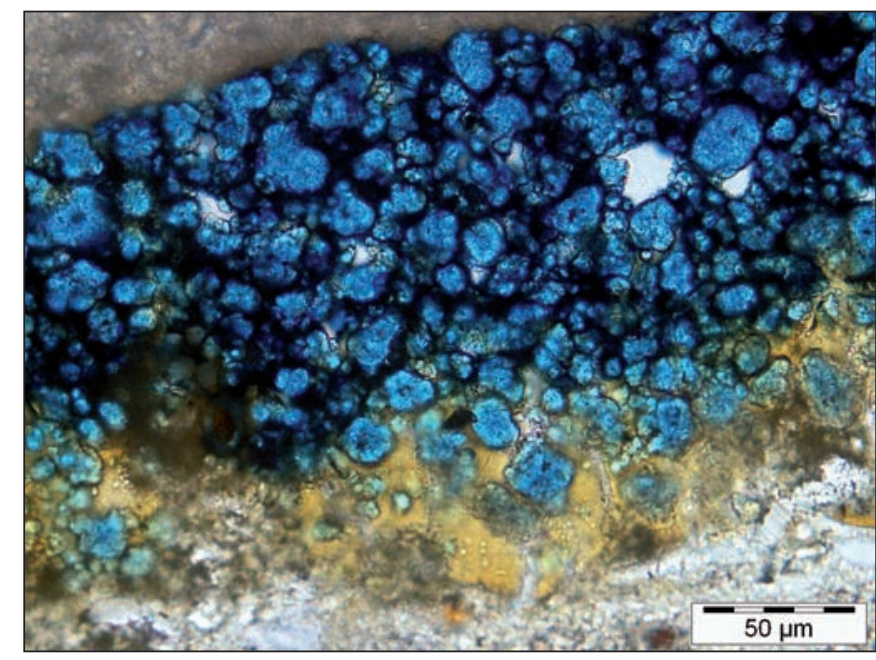

Fig. 22. Estrato de azurita sintética sobre un nivel de preparación impregnado de aceite. En este caso es característica la existencia de cristales formando texturas esferulíticas

con posterioridad a 1814, y puesto que no existen referencias de actuaciones en las policromías de la fachada hasta 1848 , consideramos que fue en esta intervención cuando debió utilizarse por primera vez este pigmento en el alero de la Fachada. Además, en ella se utilizó gran cantidad de oro en su acabado final, por lo que también puede relacionarse con la que fue objeto de duras críticas por parte de Carderera en 1848 ante el exceso de dorados y brillo que presentaba el alero (Chávez, 2004, p. 214).

Los tres niveles que suceden al F ( $\mathrm{G}, \mathrm{H}$ e I) no tienen referencias documentales claras en los archivos encontrados. Además, hay que considerar que tres intervenciones se producen en un corto espacio de tiempo, de solo 58 años, según se deduce de un documento encontrado en un hueco cegado de la fachada y que fue escrito por D. Joaquín Romero, director de los Reales Alcázares (Almagro Gorbea, com. pers.). En él se hace constar que en la intervención de 1936 no se efectuaron trabajos en las policromías de la fachada, por lo que cabe pensar que todas las actuaciones debieron efectuarse en el siglo XIX y principios del XX.

La policromía $\mathrm{G}$ podría asignarse a la intervención de 1856 o a la de 1886, y debió de servir de referencia para las indicaciones de la Real Academia de San Fernando para la intervención de 1898 que propone utilizar litargirio con el barniz preparatorio del oro. Sin embargo, en el nivel ( $\mathrm{H}$ o I) atribuible a esta intervención se utilizó pigmento de amarillo de cromo que presenta las mismas características de color y de secado, en la base preparatoria de oro, que el litargirio. 


\section{Referencias}

Almagro Gorbea, A. (2007). El Alcázar de Sevilla. Un palacio musulmán para un rey cristiano. XI Congreso de Estudios Medievales «Cristianos y musulmanes en la península Ibérica: la guerra, la frontera y la convivencia. 333365

Almagro Gorbea, A. (Coord.) (2009). La Portada del Palacio de Pedro I. Investigación y restauración. Apuntes del Alcázar de Sevilla 6, 44-67.

Almagro, A., García Bueno, A., López Cruz, O., Medina Flórez, V. (2010). Restauración de la fachada del Palacio de Pedro I. $2^{a}$ fase lateral derecho. Apuntes del Alcázar de Sevilla 11, 8-37.

Almagro, A., García Bueno, A., López Cruz, O., Medina Flórez, V. (2011). Restauración de la fachada del Palacio de Pedro I. $3^{a}$ fase lateral izquierdo. Apuntes del Alcázar de Sevilla 12. (En prensa).

Brogiolo, G.P. (1995). Arqueología estratigráfica y restauración, Informes de la Construcción, 46, no 435, 31-35.

Bruquetas, R. (2002). Técnicas y materiales de la pintura española en los siglos de oro. Ed. Fundación de Apoyo a la Historia del Arte Hispánico.

Calvo, A. (2003). Conservación y Restauración. Materiales, técnicas y procedimientos. Ed. del Serbal, Barcelona.

Chávez González, M.R. (2004). El Alcázar de Sevilla en el siglo XIX. Patronato del Real Alcazar de Sevilla, Sevilla.

Cómez Ramos, R. (2006). El Alcázar del Rey Don Pedro. Diputación de Sevilla.
Eastaugh, N., Walsh, V., Chaplin, T., Siddall, R. (2004). The pigment compendium. Optical microscopy of historical pigments. Elsevier, Amsterdan.

Gestoso Pérez, J. (1899). Guía histórico descriptiva del Alcázar de Sevilla. Escuela Tipográfica Sevillana. Sevilla.

Harley, R.D. (2001). Artists' Pigments c. 1600-1835. A study in English documentary sources. ( $2^{a}$ ed). Archetype London.

Lleó Cañal, V., García, M. (2002). El Real Alcázar de Sevilla. Patronato del Real Alcázar. Sevilla.

López Pertíñez, M.C., 2006, La Carpintería en la arquitectura Nazarí. García Bueno, A. «La Policromía en la carpintería Nazarí», pp. 68-87, Ed. Junta de Andalucía.

Manzano Martos, R. (1983). Poetas y Vida Literaria en los Reales Alcázares de la Ciudad de Sevilla. Real Academia de Buenas Letras de Sevilla.

Marín Fidalgo, A. (1990). El Alcázar de Sevilla bajo los Austrias. Guadalquivir. Sevilla.

Matteini, M., Moles, A. (2008). La química en la restauración. Los materiales del arte pictórico. (2 $\left.{ }^{\mathrm{a}} \mathrm{ed}\right)$. Nerea. San Sebastián.

Recibido: 06 de julio de 2011

Aceptado: 07 de octubre de 2011 